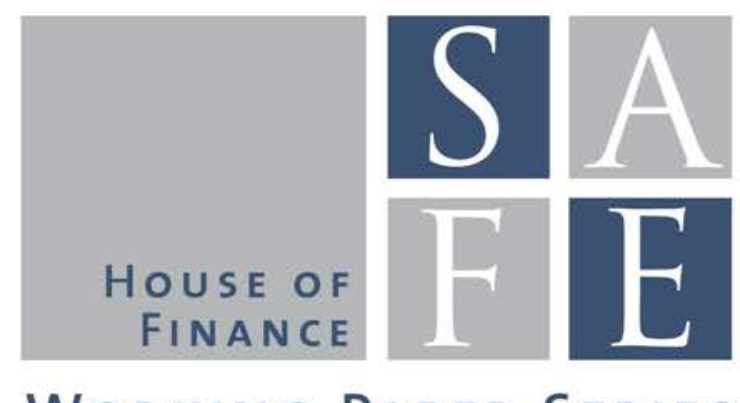

WORKING PAPER SERIES

Merlin Kuate Kamga - Christian Wilde

\title{
Liquidity premia in CDS markets
}

SAFE Working Paper No. 173

SAFE I Sustainable Architecture for Finance in Europe

A cooperation of the Center for Financial Studies and Goethe University Frankfurt 


\section{Non-Technical Summary}

The recent financial turmoil emphasizes the complexity and significance of credit and liquidity risk, and it also reveals the strong but underestimated interlinkage of both types of risks. It furthermore sheds light on the problems of credit risk and liquidity risk models applied in the area of financial risk management. The aim of our study is to understand the relation between credit risk and liquidity risk in more detail, to decompose the CDS premium into a fair CDS premium and a liquidity premium. Moreover, we intend to investigate the evolution of the estimated components over time, in particular during the financial crisis. We furthermore compare the premia of financial and non-financial institutions during different periods of the financial crisis.

We use CDS bid and ask quotes as lower and upper bounds for the default CDS premium and the bid-ask spread as sum of liquidity premia of protection buyers and protection sellers. We furthermore introduce the ask liquidity proportion defined as the ratio of the liquidity premium required by the protection sellers relative to available total liquidity given by the bid-ask spread. The model is applied on a dataset that covers a period from January 2004 to September 2010 and contains companies belonging to the iTraxx Europe. We consider five periods, each corresponding to different market conditions.

Our results show that, in periods of high credit risk (high model-implied CDS premium), protection sellers and buyers also claim larger liquidity premia which leads to an enlargement of bid ask spreads. The comovement of the liquidity premia and the model-implied CDS premium clearly infers that liquidity and credit risks are highly positively correlated, especially since the beginning of the subprime crisis in mid-2007.

The CDS mid-quotes are mostly lower than our model-CDS premia and therefore underestimate the credit risk. The discrepancy between model and market CDS spreads is larger for non-financials prior to the crisis, whereas it is larger for financials during the crisis periods.

Non-financial institutions have on average a larger default premium than financial institutions during the first three periods, i.e. pre-crisis phase, subprime phase, and systemic phase. In the recovery phase and especially during the sovereign phase, the model-implied CDS premium of financial institutions rises above the model-implied CDS premium of non-financial institutions. This can be explained by government aid and implicit bailout guarantees granted during the crisis that lose their effect with sovereigns becoming more affected themselves by the crisis.

We also analyze the share of the total liquidity captured by protection providers relatively to the protection buyers. This share better expresses the asymmetry between the cost of trading for buyers and sellers of protection. During periods of high credit risk (the systemic and the sovereign phases), protection sellers require on average a larger percentage of the total liquidity premium than in the period of declining or low model-implied CDS premium like the pre-crisis and recovery phase. Protection sellers thereby act as liquidity regulator. 
The liquidity shares of protection sellers are on average larger for financial than non-financial names in all periods except the subprime period, during which they are almost equal for both industrial sectors. The gap between financials' and non-financials' liquidity shares is particularly large during the last three periods, i.e. systemic, recovery, and sovereign phase.

The juxtaposition of the model-CDS default premia and the liquidity share of protection providers reveals three regimes. The first regime appears prior to the crisis and depicts a CDS market with a low default risk and a low percentage of total liquidity captured by the CDS sellers. The second regime occurs during the subprime phase and also during the recovery phase. The second regime is given as a state where credit markets exhibit a substantial default risk but protection providers require a small fraction of the total liquidity premia. The third regime is the worst state where default risk and liquidity deteriorate. The third regime is found in the systemic phase and in the sovereign phase. Thus, in these periods of fragile financial markets with high credit risk, in order to sell insurance, investors increase their liquidity provision relative to protection buyers. 


\title{
Liquidity premia in CDS markets*
}

\author{
Merlin Kuate Kamga and Christian Wilde ${ }^{\dagger}$
}

July 14, 2017

\begin{abstract}
We develop a state-space model to decompose bid and ask quotes of CDS into two components, fair default premium and liquidity premium. This approach gives a better estimate of the default premium than mid quotes, and it allows to disentangle and compare the liquidity premium earned by the protection buyer and the protection seller. In contrast to other studies, our model is structurally much simpler, while it also allows for correlation between liquidity and default premia, as supported by empirical evidence. The model is implemented and applied to a large data set of 118 CDS for a period ranging from 2004 to 2010. The model-generated output variables are analyzed in a difference-in-difference framework to determine how the default premium, as well as the liquidity premium of protection buyers and sellers, evolved during different periods of the financial crisis and to which extent they differ for financial institutions compared to non-financials.
\end{abstract}

\section{JEL-Classification: C22, G12}

Keywords: CDS, liquidity

*We thank Rossella Agliardi, Jack Bao, Patrick Gagliardini, Stefan Morkoetter, and seminar participants at the Financial Risks International Forum of the Institut Louis Bachelier (Paris, 2013), the conference of the Swiss Society for Financial Market Research (Zurich, 2013), the conference of the French Finance Association (Lyon, 2013), the International Risk Management Conference (Copenhagen, 2013), the Credit Risk Workshop (Basel, 2013), the AEA Conference (Philadelphia, 2014), and the WFA Conference (Monterey, 2014) for helpful comments. We gratefully acknowledge research support from the Research Center SAFE, funded by the State of Hessen initiative for research LOEWE.

${ }^{\dagger}$ Correspondence: House of Finance, Goethe University Frankfurt, Grüneburgplatz 1 (PF H29), 60323 Frankfurt am Main, Germany, Phone: +49 69798 33699, E-mails: kuatekamga@safe.uni-frankfurt.de, wilde@finance.uni-frankfurt.de. 


\section{Introduction}

The recent financial turmoil emphasizes the complexity and significance of credit and liquidity risk, and it also reveals the strong but widely underestimated interlinkage of both types of risk. It furthermore sheds light on the problems of credit risk and liquidity risk models often used in the area of financial risk management. The aim of our study is to understand the relationship between credit risk and liquidity risk in more detail, to decompose the CDS premium into a fair CDS premium and a liquidity premium, and to investigate each component separately.

The illiquidity in the credit market has been examined in numerous papers, mostly based on pre-crisis data. Longstaff, Mithal, and Neis (2005) find that the non-default component of the corporate bond spread can be mainly explained by illiquidity. They derive the default component by using the CDS mid premium. However, they assume that the CDS mid price is a pure measure of default risk and is perfectly liquid. Subsequent studies by Tang and Yan (2007), Bongaerts, de Jong, and Driessen (2011), Chen, Fabozzi, and Sverdlove (2010), Bühler and Trapp (2010) show that CDS mid quotes are actually not the pure default premium, as they contain some liquidity risk premium. Tang and Yan (2007) provide evidence of significant liquidity effects on CDS spreads. They find that the liquidity premium seems to be captured by the protection seller, and that it represents $11 \%$ of the mid quote.

Following Tang and Yan (2007), Bongaerts, de Jong, and Driessen (2011) extend the liquidity-adjusted CAPM of Acharya and Pedersen (2005) in order to investigate the liquidity risk in CDS markets. They use the bid-ask spread as a measure of liquidity and show that the liquidity premium is a statistically and economically significant component of the CDS spreads and that the protection seller gets the liquidity premium. However, neither paper can accurately estimate the level of the risk premium in the mid price and neither studies the evolution of the liquidity premium. Chen, Fabozzi, and Sverdlove (2010) and Bühler and Trapp (2010) use the liquidity intensity in a reduced-form model to price CDS contracts. This framework allows a better description of the liquidity premium dynamics, a better estimation of the pure default CDS premium, and therefore allows investigation of the relation between the credit risk and the liquidity risk in CDS contracts. Chen, Fabozzi, and Sverdlove (2010) and Bühler and Trapp (2010) estimate the liquidity risk premium in CDS markets by using bid and ask quotes. Chen, Fabozzi, and Sverdlove 
(2010) assume that the bid-ask spread is the upper bound for the liquidity premium. They set the ask premium to be equal to the fair CDS premium and assume that the illiquidity discount factor will reduce the CDS price to the bid price. They therefore exogenously give the liquidity premium to the protection buyer. Most of the above papers assume that the liquidity premium and the credit risk are uncorrelated, which has proven during the financial crisis to be a very unrealistic assumption. Moreover, they focus on American corporate data. Bühler and Trapp (2010) are the first to include the correlation between both risk factors. They extend the model of Longstaff, Mithal, and Neis (2005) by adding liquidity discount factors into the CDS pricing formula. Unlike Chen, Fabozzi, and Sverdlove (2010), they focus on European corporate data and do not assume prima facie that the protection buyer captures the liquidity premium. Actually they even find that the liquidity premium is earned by the protection seller and represents $5 \%$ of the mid price. Unfortunately, the parameter estimates are not shown, so that the performance of the model and the stability of the estimates are unclear. These are important issues, since the model relies on many parameters (12 for the CDS and 18 in total). Furthermore, they find that the premium stemming from the interlinkage of illiquidity and default risk was insignificant. However, since the beginning of the subprime crisis, the comovement of liquidity risk and default risk becomes obvious; as the CDS premium rises, the bid-ask spread widens. This comovement indicates a strong dependence of liquidity risk on credit risk.

So far, there is mixed evidence on how the liquidity premium is allocated between buyers and sellers. Our main objective is thus, by considering the correlation of credit risk and liquidity risk, to disentangle the CDS premium into the fair CDS premium and liquidity premium in a simple and robust framework and to investigate the evolution of the estimated components over time, in particular during the financial crisis. The premia are investigated and compared for both financial and non-financial institutions during different periods of the financial crisis.

We use CDS bid and ask quotes as lower and upper bounds for the default CDS premium and the bid-ask spread as sum of liquidity premium of the protection buyer and the protection seller. Elaborated upon the approach of Hasbrouck (1999) and Fulop and Lescourret (2009), our model is a state space model with log ask price and bid-ask spread of the log-prices as observed processes. We furthermore introduce the ask liquidity 
proportion, defined as the ratio of the ask liquidity premium to the bid-ask spread. Thus, instead of modeling two liquidity premia as in the aforementioned literature, we just have to use one variable. The model is applied on a dataset that covers a period from January 2004 to September 2010 and contains 118 names of companies belonging to the iTraxx Europe.

We consider five periods, each corresponding to different market conditions. The first period, labeled pre-crisis phase, ranges from January 2004 to July 2007 and covers a time of booming and liquid CDS market. We find that the model-implied fair CDS premium is on average 34.37 , while the average mid quote is 33.57 . The protection seller charges a liquidity premium of about $25.7 \%$ of the bid-ask spread, and the remainder goes to the protection buyer. The financial sector exhibits a lower proportional ask liquidity premium than the non-financial sector. The second period, named subprime phase, covers the subprime credit crisis and ranges from August 2007 to August 2008. During this period, both CDS prices and bid-ask spreads peak on March 2008 at the collapse of Bear Sterns. The model-implied CDS premium on average doubles to 70.119. The average ask liquidity proportion of protection sellers declines to $23.5 \%$ of the bid-ask spread (but with a larger volatility). The following phase, the systemic phase, ranging from September 2008 to March 2009, covers the bankruptcy of Lehman Brothers as well as the bailout of Fannie Mae, Freddie Mac, and AIG. The deteriorating credit and liquidity conditions lead to a jump of the model-implied CDS premium to 178.680 and the protection seller now requires $41.7 \%$ of the bid-ask spread. The fourth phase, the recovery phase, ranging from April 2009 to December 2009, is characterized by uncommon measures implemented by governments and central banks aimed at lowering credit risk and providing liquidity to the financial system. Consequently, the model-implied CDS premium drops from 185.717 in April 2009 to 72.620 by the end of December 2009 with an average of 103.623 while the protection seller charges $32.10 \%$ of the lower bid-ask spread. After this slight recovery of the CDS market, the worsening sovereign risk spills over to corporates and pushes up the model-implied CDS premium again from 72.620 to 113.282 during the fifth period, the sovereign phase, ranging from January 2010 to September 2010. In this phase, the protection seller requires a larger portion of the bid-ask spread (43.8\%).

We find that as the market becomes less liquid (widening liquidity risk), the protection seller and the protection buyer charge a larger liquidity premium. However, relative to the 
bid side, the protection seller acts as liquidity regulator by lowering his liquidity premium in periods of decreasing default risk and augmenting his liquidity requirement in periods of rising default risk. We furthermore show that, during the first three periods, the precrisis, subprime, and systemic phases, the fair CDS premia of financial institutions are on average lower than the non-financial sector's fair CDS premia. However, afterwards, during the recovery and sovereign phase, the higher sovereign risk spills over to financial institutions and pushes the financial sector's fair CDS premia above the non-financial fair CDS premia. The liquidity premia are on average lower for financial institutions than for non-financial institutions.

We contribute to the existing literature on liquidity risk in CDS markets by analyzing data before and during the financial turbulence, and we can therefore thoroughly understand the liquidity requirement behavior for both counterparties in a CDS contract. Unlike the recent literature, our model provides a strong and positive interlinkage of the default and the liquidity premia in the CDS market, which strengthens further after the collapse of Lehman Brothers in the systemic phase. Moreover, the major portion of the liquidity premium is allocated to the protection buyer.

The remainder of this paper is structured as follows. Section 2 presents the model and filtering procedure. Section 3 describes the CDS and market data. A preliminary analysis of the comovement of bid-ask spreads and CDS mid quotes is also carried out. In Section 4, we run the filtering and interpret the results. We also investigate the evolution of liquidity risk premia in different periods. In Section 5, we summarize and conclude.

\section{$2 \quad$ State Space Model}

\section{$2.1 \quad$ Model}

A credit default swap (CDS) is defined as an insurance contract between two counterparties for a protection against default of a name or reference entity. The protection buyer agrees to periodically (quarterly or semi-annually) pay the protection seller a premium up to maturity if the reference entity does not go bankrupt. This side of the bilateral contract is called the premium or fixed leg. If the reference firm defaults, the protection seller compensates the protection buyer for the loss incurred on the underlying asset (mostly bonds). This side of the contract is called the protection or default leg. We name 
the premium paid by the protection buyer a fair CDS premium and it is computed by matching the expected premium leg to the expected protection leg. Thus, a fair CDS premium mainly takes the following risks into account: the credit default risk of the reference name, the counterparty credit risk of the protection seller (risk that protection seller may not be able to satisfy its obligations) and the recovery rate of the underlying asset. Arora, Gandhi, and Longstaff (2012) empirically show that counterparty credit risk is priced in the CDS market, but its effect on CDS premia is economically insignificant. Concerning recovery risk, some papers such as Bakshi, Madan, and Zhang (2006), Das and Hanouna (2009), Schlaefer and Uhrig-Homburg (2010), Schneider, Soegner, and Veza (2010), Conrad, Dittmar, and Hameed (2011), and others have elaborated methods to estimate the recovery rate implied in CDS premia. Nevertheless, recovery risk in the CDS market is neglected in most studies, since it is difficult to identify the recovery rate from the default rate. Rather, the recovery rate is generally assumed to be constant and fixed at 40,50 or $60 \%$. The main driver of fair CDS premia and actually the most interesting risk that arises in the literature and for practitioners is the credit default risk of reference names. The fair CDS premium can therefore be loosely called the CDS default premium.

A CDS is a bilateral contract traded in the OTC market. Trades in CDS markets face therefore some impediments besides the default risk such as information asymmetries, transaction costs, searching costs, funding costs, etc. We collectively call these obstacles liquidity risk, and assume that it affects both the protection seller and the protection buyer. However, we account for the fact that they may be affected in an uneven way by liquidity risk and suppose that the protection seller and the protection buyer of a CDS contract set respectively the ask price $S_{t}^{a s k}$ and the bid price $S_{t}^{b i d}$ such that they can cover all the cost of trading. Therefore, $S_{t}^{a s k}$ and $S_{t}^{b i d}$ are upper and lower bounds for our model-implied CDS premium $S_{t}^{\text {def }}$. We assume that the model-implied CDS premium is the best approximation of a fair CDS premium. The bid-ask spread, $B A_{t}=$ $S_{t}^{a s k}-S_{t}^{b i d}$, therefore represents the total liquidity premium that the protection buyer and seller charge. Nevertheless, it does not tell of the liquidity premium required by each size of a trade. For instance, a widening bid-ask spread is possible in three scenarios: either the liquidity premium of the ask side narrows while the bidder requires a larger liquidity premium, or the liquidity premium of the ask side enlarges while the bidder requires a lower liquidity premium, or the liquidity premium of both sides increases. In order to 
better model the asymmetry in the liquidity premium, we define from the perspective of the protection seller a liquidity proportion labeled $R_{t}$,

$$
R_{t}=\frac{S_{t}^{a s k}-S_{t}^{d e f}}{S_{t}^{a s k}-S_{t}^{b i d}}=\frac{S_{t}^{a s k}-S_{t}^{d e f}}{B A_{t}}
$$

$0 \leq R_{t} \leq 1$ represents the liquidity premium (in relation to the bid-ask spread) that the protection seller requires to sell a CDS contract. This measure tells more about the trading behavior in CDS markets and therefore completes the information emanating from the bid-ask spread. $R_{t}$ is also a better measure of liquidity because it is a relative measure bounded on the interval $[0,1]$ and can therefore be suitable for analyzing CDS involving different ratings, periods of time, and industry sectors. It is clear that a rise of the bid-ask spread indicates an evaporation of liquidity in CDS markets while an increase of $R_{t}$ denotes an increasing ask liquidity premium relative to the protection buyer. For $R_{t}=\frac{1}{2}$, the mid CDS premium is equal to the default premium and the bid liquidity premium is equal to the ask liquidity premium (as assumed in Longstaff, Mithal, and Neis (2005)). We offer a test of this. For $R_{t} \geq \frac{1}{2}$, the protection seller requires a larger liquidity premium than the buyer. This can be motivated by the fact that he is facing a higher cost for selling protection, or as liquidity provider in CDS markets (see Tang and Yan (2007)), he needs to charge a larger liquidity premium to lower the demand to the supply of CDS. In case of higher demand for CDS contracts, according to Amihud and Mendelson (1988), the market maker wants to keep his book clear and therefore requires a higher liquidity premium for selling protection (sell expensive) and a lower liquidity premium for buying protection (buy expensive). The decision to explicitly model $R$ allows us to test whether larger default risk is associated with higher $R$, potentially due to higher insurance demand. In order to explicitly model the liquidity premium of each counterparty in a CDS contract, we use an econometric model similar to Hasbrouck (1999) and Fulop and Lescourret (2009). From Equation 1, we obtain

$$
\begin{aligned}
S_{t}^{a s k} & =S_{t}^{\text {def }}+R_{t} B A_{t}=e^{s_{t}^{d e f}}+R_{t} B A_{t}, \\
S_{t}^{\text {bid }} & =S_{t}^{\text {def }}-\left(1-R_{t}\right) B A_{t} \\
& =e^{s_{t}^{\text {def }}}-\left(1-R_{t}\right) B A_{t} .
\end{aligned}
$$

We denote by $s_{t}^{a s k}, s_{t}^{b i d}$ the logarithmized ask and bid quotes and define the correspond- 
ing bid-ask spread by $b a_{t}=s_{t}^{a s k}-s_{t}^{b i d}$. The corresponding liquidity proportion of the protection seller is given as $0 \leq r_{t}=\frac{s_{t}^{a s k}-s_{t}^{\text {def }}}{s_{t}^{a s k}-s_{t}^{\text {bid }}} \leq 1$. We further assume that there exists some liquidity discount factors $L_{t}^{a s k}$ and $L_{t}^{\text {bid }}$ satisfying the relations

$$
\begin{aligned}
S_{t}^{a s k} & =S_{t}^{\text {def }} L_{t}^{a s k} \\
S_{t}^{b i d} & =S_{t}^{d e f} L_{t}^{b i d},
\end{aligned}
$$

with $1 \leq L_{t}^{a s k}$ and $0 \leq L_{t}^{b i d} \leq 1$, such that the bid price is always lower than the ask price. It follows from Equation 4 that

$$
\begin{aligned}
\log L_{t}^{a s k} & =\log S_{t}^{a s k}-\log S_{t}^{\text {def }} \\
& =\left(\log S_{t}^{a s k}-\log S_{t}^{\text {def }}\right) \frac{\log S_{t}^{a s k}-\log S_{t}^{\text {bid }}}{\log S_{t}^{a s k}-\log S_{t}^{\text {bid }}} \\
& =\frac{\log S_{t}^{a s k}-\log S_{t}^{d e f}}{\log S_{t}^{a s k}-\log S_{t}^{\text {bid }}}\left(\log S_{t}^{a s k}-\log S_{t}^{\text {bid }}\right) \\
& =r_{t}\left(\log S_{t}^{a s k}-\log S_{t}^{\text {bid }}\right) .
\end{aligned}
$$

And analogously we get from Equation 5

$$
\log L_{t}^{b i d}=\left(r_{t}-1\right)\left(\log S_{t}^{a s k}-\log S_{t}^{b i d}\right)
$$

We can write from Equations 4 and 7

$$
\begin{aligned}
\log S_{t}^{a s k} & =\log S_{t}^{\text {def }}+\log L_{t}^{a s k} \\
& =\log S_{t}^{\text {def }}+\frac{\log S_{t}^{a s k}-\log S_{t}^{\text {def }}}{\log S_{t}^{a s k}-\log S_{t}^{\text {bid }}}\left(\log S_{t}^{a s k}-\log S_{t}^{b i d}\right) \\
s_{t}^{a s k} & =s_{t}^{\text {def }}+r_{t} b a_{t} .
\end{aligned}
$$

From Equations 5 and 8 follows the relation

$$
s_{t}^{b i d}=s_{t}^{d e f}-\left(1-r_{t}\right) b a_{t}
$$

In contrast to the approach of Hasbrouck (1999) and Fulop and Lescourret (2009), two state variables, $s_{t}^{\text {def }}$ and $r_{t}$, are sufficient to describe the fair default process and the liquidity processes of the ask and bid prices. The log-default premium satisfies the relation 
$s_{t+1}^{\text {def }}=s_{t}^{\text {def }}+\eta_{t+1}$, where $\eta_{t+1}$ is a normal random noise with variance $\sigma_{\eta}^{2}$. Longstaff, Mithal, and Neis (2005) show that the non-default component of corporate bond yields is strongly mean reverting and Chen, Fabozzi, and Sverdlove (2010) find a mean reverting behavior of the liquidity rate in corporate CDS. Based on these results, we assume that the liquidity process $r_{t}$ is a mean-reverting process bounded on [0, 1]. Following van Emmerich (2006), the liquidity process $r_{t}$ has the dynamic $d r_{t}=\kappa\left(\theta-r_{t}\right) d t+\sigma \sqrt{\left(1-r_{t}\right) r_{t}} d W_{t}$. The bounds of the stochastic process are unattractive and unattainable if $2 \kappa \geq\left(\frac{\sigma^{2}}{1-\theta}, \frac{1}{\theta}\right)$. To obtain a model that is linear in the error term, we use the first-order approximation. However, different discrete time processes are obtained depending on the discretization method applied. For example, the explicit Euler discretization gives

$$
r_{t}=\kappa \theta+(1-\kappa) r_{t-1}+\sqrt{\left(1-r_{t-1}\right) r_{t-1}} \epsilon_{t}, \quad \epsilon_{t} \sim N\left(0, \sigma_{\epsilon}\right)
$$

whereas the implicit Euler discretization yields

$$
r_{t}=\frac{\kappa \theta}{1+\kappa}+\frac{r_{t-1}}{1+\kappa}+\frac{1}{1+\kappa} \sqrt{\left(1-r_{t-1}\right) r_{t-1}} \epsilon_{t}
$$

For our calibration, we choose a general mean reverting process bounded between 0 and 1 given by the dynamic

$$
r_{t}=\alpha+\beta r_{t-1}+\sqrt{\left(1-r_{t-1}\right) r_{t-1}} \epsilon_{t}, \quad \text { with } \quad 0 \leq \alpha \leq 1,-1 \leq \beta \leq 1
$$

Since the log fair CDS premium is a random walk, by means of the first difference of the log ask price

$$
\begin{aligned}
s_{t}^{a s k}-s_{t-1}^{a s k} & =s_{t}^{d e f}-s_{t-1}^{d e f}+r_{t} b a_{t}-r_{t-1} b a_{t-1}, \\
y_{t} & =\eta_{t}+r_{t} b a_{t}-r_{t-1} b a_{t-1} .
\end{aligned}
$$

The change in ask premium $y_{t}$ given in Equation 13 represents the observation equation, and the state-variable process is driven by $r_{t}$. Since $r_{t}$ is non-linear in $r_{t-1}$ and $\epsilon$, by means of the Taylor approximation around $\hat{r}$ and 0 , we linearize the evolution of the 
relative log-liquidity premium

$$
\begin{aligned}
r_{t} & =f\left(r_{t-1}, \epsilon_{t}\right) \\
& \approx f(\hat{r}, 0)+\left.\frac{\partial f}{\partial r}\right|_{\hat{r}, 0}\left(r_{t}-\hat{r}\right)+\left.\frac{\partial f}{\partial \epsilon}\right|_{\hat{r}, 0}\left(\epsilon_{t}-0\right) \\
& =\alpha+\beta r_{t-1}+\sqrt{(1-\hat{r}) \hat{r}} \epsilon_{t} \\
& =\alpha+\beta r_{t-1}+\sqrt{\left(1-r_{t-1 \mid t-1}\right) r_{t-1 \mid t-1}} \epsilon_{t} \\
& =\alpha+\beta r_{t-1}+\sqrt{(1-\hat{r}) \hat{r}} \epsilon_{t}, \quad \text { with } \quad \hat{r}=r_{t-1 \mid t-1} \\
& =\alpha+\beta r_{t-1}+\hat{L}_{t-1} \epsilon_{t}, \quad \text { with } \quad \hat{L}_{t-1}=\sqrt{(1-\hat{r}) \hat{r}}
\end{aligned}
$$

\subsection{Kalman Filtering}

Given that we avoid a strongly non-linear model as in Fulop and Lescourret (2009), the Kalman filter is used to estimate the unobserved liquidity process $r_{t}$. The Kalman filter is a robust and recursive approach to estimate non-observable state variables in linear dynamics systems. It provides a minimum mean squared error of $r_{t}$ (see Simon (2006) and Kim and Nelson (1999)). We rewrite the observation equation 13 as

$$
\begin{aligned}
y_{t} & =r_{t} b a_{t}-r_{t-1} b a_{t-1}+\eta_{t} \\
& =\underbrace{\left[b a_{t}-b a_{t-1}\right.}_{H_{t}}] \underbrace{\left[\begin{array}{c}
r_{t} \\
r_{t-1}
\end{array}\right]}_{x_{t}}+\eta_{t} \\
& =H_{t} x_{t}+\eta_{t} .
\end{aligned}
$$

The observation or measurement equation gives the relation between the observed process $y_{t}$ and and the state variables $x_{t}$. The dynamics of $x_{t}$ is derived from Equation 15 and given by

$$
\begin{gathered}
r_{t}=\alpha+\beta r_{t-1}+\hat{L}_{t-1} \epsilon_{t} \\
\underbrace{\left[\begin{array}{c}
r_{t} \\
r_{t-1}
\end{array}\right]}_{x_{t}}=\underbrace{\left[\begin{array}{l}
\alpha \\
0
\end{array}\right]}_{A}+\underbrace{\left[\begin{array}{ll}
\beta & 0 \\
1 & 0
\end{array}\right]}_{F} \underbrace{\left[\begin{array}{c}
r_{t-1} \\
r_{t-2}
\end{array}\right]}_{x_{t-1}}+\underbrace{\left[\begin{array}{cc}
\hat{L}_{t-1} & 0 \\
0 & 0
\end{array}\right]}_{L_{t-1}} \underbrace{\left[\begin{array}{c}
\epsilon_{t} \\
0
\end{array}\right]}_{w_{t}}
\end{gathered}
$$


Hence, the transition equation is written as

$$
x_{t}=A+F x_{t-1}+L_{t-1} w_{t}
$$

Our state space model can then be summarized as follows

$$
\begin{aligned}
& y_{t}=H_{t} x_{t}+\eta_{t}, \\
& x_{t}=A+F x_{t-1}+L_{t-1} w_{t} .
\end{aligned}
$$

The measurement noise process $\eta_{t}$ and the state variable noise process $w_{t}$ are white, have zero-mean and are correlated with covariance matrices respectively given by $\sigma_{\eta}^{2}$ and $Q$. In the model, we allow for correlation between the default premium and liquidity. In particular, we denote by $M$ the correlation matrix between $\eta_{t}$ and $w_{t}$. It holds that

$$
\begin{aligned}
& \eta_{t} \sim N\left(0, \sigma_{\eta}^{2}\right), \\
& w_{t} \sim N(0, Q) \quad Q=\left[\begin{array}{cc}
\sigma_{\epsilon}^{2} & 0 \\
0 & 0
\end{array}\right], \\
& M=\operatorname{Cov}\left[w_{t}, \eta_{t}\right]=\left[\begin{array}{c}
\rho_{\epsilon, \eta} \sigma_{\epsilon} \sigma_{\eta} \\
0
\end{array}\right] .
\end{aligned}
$$

The Kalman filter is a recursive procedure of prediction or forecasting and updating steps. At time $t \in \mathbb{N}, x_{t+1 \mid t}$ denotes the predicted state variable and represents the estimate of $x_{t+1}$ given that information or measurements are available up to time $t$. Thus, it holds that $x_{t+1 \mid t}=E\left[x_{t+1} \mid y_{1}, \cdots, y_{t}\right]$. At time $t+1$, the measurement $y_{t+1}$ is available and we update the estimate of the state variable $x_{t+1}$ by taking the new observation into account. We have $x_{t+1 \mid t+1}=E\left[x_{t+1} \mid y_{1}, \cdots, y_{t+1}\right]$

\section{Forecasting}

The predicted or a priori estimate of the state and observed variables are given by

$$
\begin{aligned}
& x_{t+1 \mid t}=A+F x_{t \mid t}, \\
& y_{t+1 \mid t}=H_{t+1} x_{t+1 \mid t} .
\end{aligned}
$$


We denote by $P_{t+1 \mid t}$ the prediction error covariance matrix and it is defined by

$$
P_{t+1 \mid t}=E\left[\left(x_{t+1}-x_{t+1 \mid t}\right)\left(x_{t+1}-x_{t+1 \mid t}\right)^{\prime}\right]
$$

The corresponding updating error covariance matrix is defined by

$$
P_{t \mid t}=E\left[\left(x_{t}-x_{t \mid t}\right)\left(x_{t}-x_{t \mid t}\right)^{\prime}\right]
$$

It follows from Equations 18 and 19, the following relation

$$
\begin{aligned}
P_{t+1 \mid t} & =E\left[\left(x_{t+1}-x_{t+1 \mid t}\right)\left(x_{t+1}-x_{t+1 \mid t}\right)^{\prime}\right] \\
& =E\left[\left(F x_{t}+L_{t} w_{t+1}-F x_{t \mid t}\right)\left(F x_{t}+L_{t} w_{t+1}-F x_{t \mid t}\right)^{\prime}\right] \\
& =F E\left[\left(x_{t}-x_{t \mid t}\right)\left(x_{t}-x_{t \mid t}\right)^{\prime}\right] F^{\prime}+L_{t} E\left[\left(w_{t+1}\right)\left(w_{t+1}\right)^{\prime}\right] L_{t}^{\prime} \\
& =F P_{t \mid t} F^{\prime}+L_{t} Q L_{t}^{\prime} .
\end{aligned}
$$

Using again Equations 18 and 19, the observation prediction error covariance $V_{t+1}$ of the observed process $y_{t}$ is derived:

$$
\begin{aligned}
V_{t+1} & =E\left[\left(y_{t+1}-y_{t+1 \mid t}\right)^{2}\right] \\
& =E\left[\left(H_{t+1} x_{t+1}+\eta_{t+1}-H_{t+1} x_{t+1 \mid t}\right)^{2}\right] \\
& =E\left[\left(H_{t+1}\left(x_{t+1}-x_{t+1 \mid t}\right)+\eta_{t+1}\right)^{2}\right] \\
& =H_{t+1} E\left[\left(x_{t+1}-x_{t+1 \mid t}\right)\left(x_{t+1}-x_{t+1 \mid t}\right)^{\prime}\right] H_{t+1}^{\prime}+E\left[\eta_{t+1}^{2}\right]+E\left[2 H_{t+1}\left(x_{t+1}-x_{t+1 \mid t}\right) \eta_{t+1}\right] \\
& =H_{t+1} E\left[\left(x_{t+1}-x_{t+1 \mid t}\right)\left(x_{t+1}-x_{t+1 \mid t}\right)^{\prime}\right] H_{t+1}^{\prime}+E\left[\eta_{t+1}^{2}\right]+E\left[2 H_{t+1} L_{t} w_{t+1} \eta_{t+1}\right] \\
& =H_{t+1} P_{t+1 \mid t} H_{t+1}^{\prime}+R+2 H_{t+1} L_{t} M, R=\sigma_{\eta}^{2}
\end{aligned}
$$

After predicting the state variables, the second step in Kalman procedure is to update the estimates given new observation. 


$$
\begin{aligned}
K_{t+1} & =\left(P_{t+1 \mid t} H_{t+1}^{\prime}+L_{t} M\right)\left(H_{t+1} P_{t+1 \mid t} H_{t+1}^{\prime}+R+H_{t+1} L_{t} M+L_{t}^{\prime} M^{\prime} H_{t+1}^{\prime}\right)^{-1} \\
& =\left(P_{t+1 \mid t} H_{t+1}^{\prime}+L_{t} M\right)\left(H_{t+1} P_{t+1 \mid t} H_{t+1}^{\prime}+R+2 H_{t+1} L_{t} M\right)^{-1}, \\
x_{t+1 \mid t+1} & =x_{t+1 \mid t}+K_{t+1}\left(y_{t+1}-y_{t+1 \mid t}\right) \\
P_{t+1 \mid t+1} & =P_{t+1 \mid t}-K_{t+1}\left(H_{t+1} P_{t+1 \mid t}+\left(L_{t} M\right)^{\prime}\right) .
\end{aligned}
$$

For a thorough reading on filtering methods refer to Simon (2006). Before filtering out the state variable $x_{t \mid t}$, the parameters $A, F, Q, R, M$ and the start values $x_{0 \mid 0}, P_{0 \mid 0}$ should be known. We therefore estimate the parameters by means of the maximum likelihood method. The multivariate distribution of the observation can be written as

$$
\begin{aligned}
& f\left(y_{1}, \ldots, y_{T}\right)=f\left(y_{1}\right) f\left(y_{2} \mid y_{1}\right) f\left(y_{3} \mid y_{1}, y_{2}\right) \ldots \\
& f\left(y_{T-1} \mid y_{1}, y_{2}, \ldots, y_{T-2}\right) f\left(y_{T} \mid y_{1}, y_{2}, \ldots, y_{T-2}, y_{T-1}\right) .
\end{aligned}
$$

Given that $\eta_{t}$ and $w_{t}$ are normally distributed, $y_{t+1}$ conditional on $y_{1}, y_{2}, \ldots, y_{t}$ is normally distributed with mean $y_{t+1 \mid t}$ and variance $V_{t+1}$. Hence,

$$
f\left(y_{t+1} \mid y_{1}, y_{2}, \ldots, y_{t-1}, y_{t}\right)=\frac{1}{\sqrt{(2 \pi)} \sqrt{V_{t+1}}} \exp \left[-\frac{1}{2} \frac{\left(y_{t+1}-y_{t+1 \mid t}\right)^{2}}{V_{t+1}}\right]
$$

The $\log$-likelihood function $L=\log \left(f\left(y_{1}, \ldots, y_{T}\right)\right)$ is written as

$$
L=-T \frac{\log (2 \pi)}{2}-\frac{1}{2} \sum_{t=1}^{T} \log V_{t+1}+\frac{\left(y_{t+1}-y_{t+1 \mid t}\right)^{2}}{V_{t+1}}
$$

and is maximized according to the parameters $\Theta=\left[\begin{array}{lllllll}\sigma_{\eta} & \alpha & \beta & \sigma_{\epsilon} & \rho & r_{0 \mid 0} & P_{0 \mid 0}\end{array}\right]$. In order to better approximate the global maximum, we start the filtering by choosing $N=$ 200 initial parameter vectors $\Theta_{0}^{1}, \ldots, \Theta_{0}^{N}$. The parameters are estimated with a three-step procedure:

1. For each initial parameter set $\Theta_{0}^{k}, k=1, \ldots, N$, we use the Kalman filter to generate a time series of both $y_{t+1 \mid t}$ and $x_{t \mid t}, t=1, \ldots, T$, and find optimal parameters $\hat{\Theta}^{k}$, $k=1, \ldots, N$, that maximize $L$ for the observed $y_{t}$.

2. Thereafter, the parameter set $\hat{\Theta}$ is chosen from $\left\{\hat{\Theta}^{1}, \ldots, \hat{\Theta}^{N}\right\}$ as the parameter set 
that provides the maximum value for $L$.

3. We reinitialize the procedure by setting $\Theta_{0}^{1}=\hat{\Theta}$ and generate $N-1$ parameter sets $\Theta_{0}^{2}, \ldots, \Theta_{0}^{N}$ and return to the first step. As soon as the parameters converge, we stop the procedure.

\section{Data}

\subsection{CDS Data}

We use a dataset of weekly corporate CDS bid and ask prices from Datastream. The dataset covers the period January 2004 - September 2010 and contains 118 5-year CDS names from the iTraxx Europe. Our sample therefore consists of frequently traded CDS contracts. It covers several groups: automobile and industry (29 names), consumer and service (26), financials (23), energy (20), telecommunications (20). Summary statistics of the data are given in Figure 1 and Table 1. Time-series of CDS mid quotes, bid-ask spreads, and relative bid-ask spreads are depicted in Figure 1, and the corresponding numbers are reported in Table 1. We divide the sample into five periods, representing different phases of the financial crisis and different market conditions. The five phases are the pre-crisis phase, subprime phase, systemic phase, recovery phase, and sovereign phase.

The pre-crisis phase begins in January 2004 and ends in July 2007. As Figure 1 illustrates, this period is characterized by a steady decline in CDS prices and a lower volatility (see also Table 1, second column). The International Swap and Derivative Association (ISDA) market survey ${ }^{1}$ reports a strong and sustained growth in CDS markets during this first phase. The outstanding amount of CDS rises from 5.44 trillion in the first half of 2004 to $\$ 45.46$ trillion in first half of 2007 . The higher demand and supply of protection lead to very liquid CDS markets and lower bid-ask spreads with an average of 3.556. Table 1 also suggests that the absolute bid-ask spread is positively correlated with the CDS mid premium (0.590), whereas the relative bid-ask spread moves negatively with the CDS mid price $(-0.347)$. This highlights that there is a relation between the CDS premium and the liquidity premium, and it demonstrates the importance of explicitly

\footnotetext{
${ }^{1}$ www.isda.org/statistics/recent.html
} 
modeling this relation.

This period of flourishing and quiet CDS markets is followed by the financial crisis which covers four periods. The subprime phase ranges from August 2007 to August 2008 and covers the subprime credit crisis. Given that financial markets are highly connected and European financial institutions have large exposures in American mortgage backed securities and derivatives during that period, the subprime crisis spills over from US to European markets. The average CDS price doubles from 33.570 to 68.824 basis points, and its volatility also rises from 31.189 to 41.592. Simultaneously, the bid-ask spread climbs by $46 \%$ from 3.556 to 5.207 . During this period, the CDS mid premium and the bid-ask spread peak on March 2008 while Bear Stearns collapses. From this period on, the CDS mid premium and the absolute bid-ask spread strongly comove with a correlation larger than 0.69 and which peaks during the systemic phase. The outstanding notional value of CDS contracts reaches its highest level in the second half of 2007 (\$62.17 trillion) and declines to $\$ 54$ trillion in the first half of 2008. If we assume that the CDS contracts are almost standardized at $\$ 10$ million notional values, a larger outstanding amount therefore implies more CDS contracts compared to the previous phase. Although the credit market is going through a turbulent period, enough confident investors or speculators are still capable of providing protection to the increasing demand of insurance against the rising default risk.

The third period, the systemic phase, ranging from September 2008 to March 2009, is a period of severe systemic risk catalyzed by the bankruptcy of Lehman Brothers on September 15, 2008. Stock prices all over the world plummet, the index of global risk aversion measured by Caceres, Guzzo, and Segoviano (2010) jumps by 21\%, and the Libor-OIS spread rises significantly. The average CDS price sharply climbs to more than 178, with a dispersion that grows from 41.592 during the subprime phase to 182.795 . The bid-ask spread also triples to 14.827 . Thus, this implies that both credit quality and liquidity worsen at the same time. The outstanding notional amount sharply declines by about $29 \%$ by the end of 2008 . The fragile credit market, the high default probability combined with the large risk aversion, and the low funding liquidity available combine to push the protection seller to shy away from risky assets and thus damp down the liquidity of the CDS market. In order to appease the jumpy market, the USA and many European countries intervene by introducing new policy rules such as stimulus packages, 
by providing guarantees for risky assets, and by bailing out or nationalizing financial institutions. In September 2008, for example, Fannie Mae and Freddie Mac are placed by the U.S. Treasury into conservatorship of the U.S. government. The Federal Reserve provides AIG with $\$ 85$ billion bailout and announces the Troubled Asset Relief Program (TARP) which allows the purchase of illiquid assets. In October 2008, Germany provides a 50 billion Euro bailout to Hypo Real Estate and Belgium, France, and Luxemburg provide a 150 billion Euro guarantee of Dexia's debt. These governments' responses to the financial crisis aim at supplying liquidity and at diminishing the systemic risk in the market and thus achieve to lower the CDS prices from April 2009 to December 2009. This latter period is labeled the recovery phase. During this period, the price of default protection and its dispersion fall respectively to 102.472 and 77.933 on average. Similarly, the bid-ask spread and its dispersion also slightly decrease. The outstanding notional amount remains almost constant above $\$ 30$ trillion. However as Acharya, Drechsler, and Schnabl (2010) point out, these government interventions on the one hand stabilize financial markets, but on the other hand, they allow the transmission of risk from the financial sector to sovereigns.

It follows in several cases the degradation of sovereign creditworthiness and a successive rating downgrade of many European countries such as Greece, Ireland, Italy, Portugal and Spain. Given that a downgrade of a country generally leads to a downgrade of most home companies, and given interdependencies and the risk of contagion, the prices of CDS contracts, especially for financial institutions, climb again during the last period (sovereign phase) from January to September 2010. The outstanding notional slightly decreases to about $\$ 27$ trillion.

By observing the strong comovement of the bid-ask spread with the mid CDS premium during the financial downturn, we conjecture that market liquidity can be partly explained by default risk. The bid-ask spread is a measure of an asset's liquidity and indicates how easy or at which cost this asset can be traded. As previously forementioned, it is one measure of market liquidity. During the financial turmoil, the bid-ask spread increases with the CDS mid premium and peaks in the period following Lehman Brothers' bankruptcy. We therefore investigate the relation of the CDS liquidity premium and the default premium during the five periods proposed. Focusing on the bond market, Dick-Nielsen, Feldhütter, and Lando (2011) note a rise in liquidity premia in investment 
grade corporate bonds during the crisis. Furthermore, the substantial positive correlation between CDS mid quotes and the absolute bid-ask spread, and the negative correlation between CDS mid quotes and the relative bid-ask spread, suggests that the CDS market faces larger cost of trading as the default risk broadens and supports our model choice to include the correlation between the pure default and the liquidity variables. In the next section, we calculate the unobserved CDS premium reflecting default risk, and also the liquidity premium of the protection seller and buyer.

\section{Calibration Results}

\subsection{Parameter Estimates}

The calibration is run on the log CDS premia, and the parameter estimates for the entire sample are reported in Table 2. The average volatility of the log CDS premium (state variable $\left.s_{t}\right), \sigma_{\eta}$, exhibits during the first phase the lowest level of 0.08 . It rises to 0.13 in the subprime phase and reaches its maximum 0.14 in the systemic phase. During the fourth phase, the corporates recover and the volatility of the log default premium decreases by about $50 \%$ to 0.08 as in the first period. During the sovereign phase, because of a high correlation between country risk and corporate default risk as expounded in Section 3, the market becomes more risky and the volatility of the default premium slightly increases to 0.09. The estimated volatilities match quite well the CDS premia and bid-ask-spread evolution of Table 1 . Table 2 also shows that the volatility $\sigma_{\epsilon}$ of the relative $\log$ liquidity premium process (liquidity state variable) $r_{t}$ follows a similar path to the log fair premium volatility. However, in contrast to the default process volatility which slightly increases from 0.13 to 0.14 , the liquidity process volatility jumps by more than $60 \%$ from 0.66 in the subprime phase to 1.10 in the systemic phase. Afterwards, the volatility of the liquidity process does not recover and reaches its maximum level 1.29 during the sovereign period. The large volatility of the liquidity process during the systemic, recovery and sovereign phases draws out the general uncertainty in the market since Lehman Brothers' bankruptcy and underlines how important liquidity issues have become after the beginning of the crisis in 2007. It additionally supports the idea that the bankruptcy of Lehman Brothers changes systematically the trading behaviors in CDS markets. 
Table 2 furthermore reports a high negative and significant correlation between the default process and liquidity process. According to these results, it seems more realistic to include a correlation between the default and the liquidity premium when modeling CDS prices. To better interpret the interconnection between default risk and liquidity, we compute the sample correlation between the proportion of the liquidity premium attributable to the ask side $\left(R_{t}\right)$ and the model-implied CDS premium $S_{t}^{\text {def }}$ (see Table 3 ). The average correlation of the ask liquidity proportion $R_{t}$ of the protection seller and the model-implied CDS premium $S_{t}^{\text {def }}$ is low during the five phases but changes its sign from slightly negative to slightly positive values $-0.09,-0.07,-0.02,0.04$ and 0.1 . These low correlations suggest that the ask liquidity proportion weakly depends on the default risk. We notice in Section 3 that the bid-ask spread positively comoves with CDS mid premia, which implies that liquidity decreases as default risk increases. Similarly to bid-ask spread, the correlations between the default premium $S_{t}^{\text {def }}$ and the ask liquidity premium $S L_{t}^{a s k}=S_{t}^{a s k}-S_{t}^{\text {def }}$ and between the default premium and the bid liquidity premium $S L_{t}^{b i d}=S_{t}^{d e f}-S_{t}^{b i d}$ are positive during the five phases for most corporates. Thus, the larger the credit risk, the larger is the liquidity premium required by the protection seller and the protection buyer. During the ongoing financial crisis, the default risk goes in line with a worsening liquidity in the CDS market, i.e. a widening bid-ask spread. However, default risk seems to be unrelated to the inequality of the liquidity premium required by the seller and buyer of protection.

Table 2 displays the estimated parameters separately for financials and non-financials. The numbers show that the default state variable's volatilities $\sigma_{\eta}$ are on average in all phases higher for financial names than for non-financial names, whereas the liquidity variable's volatilities $\sigma_{\epsilon}$ are on average larger for non-financial companies except during the subprime phase. Moreover, the long run averages of the liquidity variables $\alpha$ are lower for the financial sector and thus signal a lower liquidity premium for the protection sellers on financial entities. It is also noteworthy that during the second phase, both sectors exhibit an almost equal $\alpha$. The second period corresponds to the beginning of the financial crisis and covers the subprime credit crisis that lays some ambiguity on financial institutions' default probabilities and thus increases the investors' disagreement on banks' real credit worthiness. This could damp down the willingness of financiers to sell protection on financial institutions. There is a very low $\alpha$ for financials during the 
recovery phase, indicating a low ask liquidity proportion.

\subsection{Analysis of Premia}

\subsubsection{Default premia and absolute liquidity premia}

The applied model further yields time-series of default and liquidity premia. The properties of these premia, their comovement in each phase, and their behavior for different sectors (financial and non-financial) can be analyzed. Figure 2 plots the time-series of the model-implied CDS premium $S_{t}^{\text {def }}$, ask liquidity premium $S L_{t}^{a s k}$ and bid liquidity premium $S L_{t}^{b i d}$, averaged over names. As the model-implied CDS premium rises, the protection seller and buyer also claim a larger liquidity premium which leads to an enlargement of the bid ask spread. Before August 2007, during the pre-crisis period, the model-implied CDS premium, $S_{t}^{\text {def }}$, has an average of 34.370 (see Table 4) and the ask and bid liquidity premia are around 0.994 (3.3\% of $\left.S_{t}^{\text {def }}\right)$ and 2.600. The deterioration of credit risk in the market due to the subprime crisis pushes up the average model-implied CDS premium to 70.119 during the second period. The ask and bid liquidity premia also increase respectively to 1.308 and 3.898. During the following period, the systemic phase, the average model-implied CDS premium peaks at 178.680. Given the turbulence in the market after the bankruptcy of Lehman Brothers, the protection seller more than triples its liquidity premium to 6.951 whereas the protection buyer only doubles its liquidity premium at 7.875 . The market recovery in the following phase reduces the average model-implied CDS premium, the average ask and bid liquidity premia respectively to 103.623, 2.772 and 5.074. The last period, the sovereign phase, is characterized by the fact that the model-implied CDS premium on average shrinks to 101.652. However, Table 4 also shows that only the non-financial sector has a lower model-implied CDS premium in the sovereign phase (95.614), whereas the model-implied CDS premium of financial institutions jumps on average to 126.593 . This is certainly related to the increasing sovereign risk in several European countries.

Figure 5 and the estimated positive values of skewness in Table 4 reveal that the distributions of the average model CDS premia are right skewed and vary systematically according to the phases. Besides, the model-implied CDS premium has its lowest standard deviation (31.425) before August 2007, during the pre-crisis period. Thereafter, it gradually climbs and peaks in the systemic phase of the crisis (181.198), following which 
it gradually descends (58.824). Apart from the sovereign period, the standard deviation of the CDS premium is always lower for financials compared to non-financials.

By observing Panel A and B in Figure 2, we see that the bid liquidity premium is on average larger than the ask liquidity premium. Moreover, the comovement of the liquidity premia and the model-implied CDS premium clearly infers that liquidity and credit risks are highly positively correlated, especially since the beginning of the subprime crisis in mid 2007. This contrasts with Chen, Fabozzi, and Sverdlove (2010) who find that the model-implied CDS premium is mostly not related to the liquidity premium. The bid liquidity premium is mostly larger than the ask liquidity premium.

Figure 2, Panel A, and the first column of Table 4 illustrate that non-financial institutions have on average a larger default premium than financial institutions during the first three periods, i.e. pre-crisis phase, subprime phase, and systemic phase. In the recovery phase and especially during the sovereign phase, the model-implied CDS premium of financial institutions rises above the model-implied CDS premium of non-financial institutions (see Table 4 and Panel A in Figure 2). The worsening credit quality in the financial sector is related to increasing sovereign risk, which spills over to financial institutions. A BIS study examines the impact of sovereign risk on financial institutions (see Panetta et al. (2011)). This study lists various channels through which sovereign risk may spill over to the financial sector. For instance, banks hold sovereign debt in their portfolio and any downgrade of the countries increases the riskiness of the banks. Moreover, in markets of repurchase agreements, investors commonly use government bonds as collateral in order to get funding. An increase of sovereign risk automatically leads to an augmentation of the repo rates and haircuts. Thus, liquidity dries out in the market. In addition, given the illiquidity of sovereign indices, market participants seem to use financial indices to hedge sovereign risks and therefore strengthen the comovement of sovereign and financial risks. Thus, the increase of the interlinkage of financial and sovereign risks, the growth of funding costs and the deterioration of sovereign portfolios could motivate the increase of the financial model-implied CDS premium over the non-financial CDS fair value during the last phase. This suggests that investors believe the industrial sector to be stabilized but are less confident with financial companies and thus require a larger model-implied CDS premium.

In Panel B of Figure 2, we observe that the ask liquidity premium is on average lower 
for financial institutions than for non-financial institutions and moreover, the gap between the ask liquidity premium of financials and non-financials rises during the systemic and recovery phases of the economic downturn. Figure 2, Panel C, indicates that the bid liquidity premium for the financial and non-financial sector seems to hover around the same levels.

\subsubsection{Relative bid-ask spread, relative ask liquidity and bid liquidity premia}

Figure 3, Panel A, shows the evolution of the relative bid-ask spread $B A_{t, r e l}^{\text {def }}$ over time, calculated as average over the names. Panel B and C of Figure 3 shows the decomposition of the relative bid-ask spread into ask $\left(S L_{t, r e l}^{a s k}\right)$ and bid $\left(S L_{t, \text { rel }}^{\text {bid }}\right)$ liquidity components. Overall, the relative bid-ask spread decreases during the crisis. While financials on average exhibit a larger relative bid-ask spread than non-financials during the pre-crisis period, their spreads falls below that of non-financials in later periods. The decomposition shows that during the crisis, the gap between financials and non-financials is larger for the relative ask premium than for the relative bid-premium.

The histograms in Figure 6 and the numbers in Table 4 show that dispersion of the relative bid-ask spread steadily decreases starting from the pre-crisis period (0.107) and reaches a low in the sovereign period (0.023). A steadily decreasing relative bid-ask spread can be observed for both financials and non-financials. The drop is strongest for financials (from 0.116 to 0.014 ) compared to non-financials (from 0.102 to 0.024 ).

The histogram in Figure 7 shows that for both financials and non-financials, the distributional properties of the relative bid liquidity premium are very similar to that of the relative bid-ask spread. In all cases, both mean and dispersion decrease over time.

The relative ask liquidity premium, however, differs substantially. The histograms in Figure 8 show that the shape of the distributions varies in each period. The dispersion of financials' relative ask liquidity premium shrinks from the pre-crisis phase to the sovereign phase. In contrast, for non-financials, there is a peak of mean and dispersion in the systemic phase. While both mean and dispersion are larger for financials during the first periods (pre-crisis phase and subprime phase), they are larger for non-financials during the following periods. 


\subsubsection{Ask liquidity proportion}

Table 4, Figure 4, Panel A, and Figure 9 describe the distributional properties of the ask liquidity proportion $R_{t}$ defined as the ratio of the ask liquidity premium to the bid-ask spread. We suppose $R_{t}$ better expresses the asymmetry between ask and bid liquidity premia. During the pre-crisis period, the average ask liquidity proportion $R_{t}$ hovers around its mean of $25.7 \%$ and ranges between $0.6 \%$ and $57.3 \%$ (see Table 4). Although the default risk obviously increases during the subprime phase as indicated in the previous subsection, the mean of $R_{t}$ diminishes to $23.5 \%$, however the maximal average ask liquidity proportion reaches $76.4 \%$.

Figure 4, Panel A depicts in addition an increase in the volatility. The average proportional liquidity has a mean that jumps to $41.7 \%$ in the systemic phase. Thus selling protection becomes more expensive and the ask liquidity premium reaches $97.3 \%$ of the bid-ask spread for some names. Given the market recovery during the next period, protection sellers react by easing the trade and consequently requires a lower liquidity risk premium relative to the bid-ask spread for most names. The mean of $R_{t}$ consequently drops to $32.1 \%$; however, selling protection on some names remains expensive and can reach $82.9 \%$ on average. During the last period, the sovereign phase, the average ask liquidity premium ranges now between $2.9 \%$ and $94.20 \%$ of the bid-ask spread with a mean that climbs to $43.8 \%$. During periods of high credit risk (the systemic and the sovereign phases), the protection seller requires on average a larger percentage of the bid ask spread than in the period of declining or low model-implied CDS premium like the pre-crisis and recovery phase. Besides, Figure 4, Panel A, seems to depict a difference between financial and non-financial institutions. The protection seller requires a larger relative liquidity premium for non-financial names than for financial names in all periods except the subprime period, where both industrial sectors exhibit an almost equal ask liquidity premium proportion. The difference is particularly large during the last three periods, i.e. systemic, recovery, and sovereign phase.

Figure 9 illustrates the distributions of $R_{t}$ for financial and non-financial institutions and for different periods. We first notice that the distributions are similar for both industrial sectors. During the pre-crisis and subprime phases, financial and non-financial institutions have right skewed $R_{t}$ values. Thus, selling protection is generally cheap. However, during the systemic phase of the financial crisis, the ask liquidity proportions are 
scattered on the unit interval and thus indicate a considerable more expensive protection selling, especially for non-financial institutions. This could be related to the unorthodox measures and bailout policies applied by several European governments to save financial institutions and provide liquidity in the financial markets. Thereafter we observe that most values of the ask liquidity proportion are concentrated near the lower bound during the recovery phase, however the non-financial institutions have a larger dispersion. The distribution in the next period, the sovereign period, looks similar to the systemic phase with large dispersion. The ask liquidity proportion $R_{t}$ covers all the unit interval indicating that selling protection is more expensive. During different phases of the financial downturn, protection sellers seem to require lower liquidity premium for financial than non-financial institutions.

\subsubsection{Deviation of CDS mid quotes from model-implied CDS premia}

Figure 4, Panel B shows the difference between mid and model CDS premia $\left(\Delta S_{t}\right)$. For both financials and non-financials, the fluctuations of $\Delta S_{t}$ are rather low during the precrisis phase and increase substantially during the following crisis periods. While in the pre-crisis phase the difference is larger for non-financials, it is larger for financials during the crisis periods. For financials, the difference is always negative, i.e. the model default premium is larger than the mid quote. For non-financials, the difference is also mostly negative, with the exception of certain occasions in the systemic and the sovereign phase.

Figure 10 and Table 4 show that the standard deviation of $\Delta S_{t}$ rises from 0.89 (nonfinancials) and 0.41 (financials) in the pre-crisis phase to a peak of 6.33 (non-financials) and 3.42 (financials) in the systemic phase, and subsequently drops again. Overall, the difference between mid quotes and model spreads is negative on average in all periods for both financials and non-financials. The median deviation for financials is largest in the systemic period $(-2.61)$, and for non-financials in the subprime phase $(-1.33)$.

\subsubsection{Evolution of liquidity premia in different phases of the financial crisis}

We now turn to an investigation of the evolution of liquidity premia over time, in particular during different phases of the financial crisis. We perform a formal statistical analysis of the main variables obtained as output of our model (model-implied CDS premium $S_{t}^{\text {def }}$, proportion of liquidity premium attributable to the ask side $R_{t}$, absolute ask liquidity pre- 
mium $S L_{t}^{a s k}$, absolute bid liquidity premium $S L_{t}^{b i d}$, and relative bid-ask spread $B A_{t, r e l}^{\text {def }}$ ). A difference-in-difference framework is applied, with financial institutions as treatment group, non-financial institutions as control group, the pre-crisis period as reference period, and several periods during the crisis. For this, we apply several random-effect panel regressions, one for each variable from our model. The results are given in Table 5.

The results for the model-implied CDS premium are in the first section of Table 5. The numbers show that, overall, the model-implied default premium increased during the crisis and reached a maximum in the systemic period. Financial institutions have a significantly lower default premium than non-financials. Moreover, the interaction terms for financial institutions show that financials have comparatively low default premia during the systemic crisis period, and comparatively large default premia during the sovereign crisis period. This can be explained by government aid and implicit bailout guarantees granted during the crisis that lose their effect with sovereigns becoming more affected by the crisis themselves. Essentially all coefficients in this regression are significant.

The next section of Table 5 shows the regression results for the proportion of the liquidity premium attributable to the ask side, $R_{t}$. The numbers show that $R_{t}$ increased significantly after the collapse of Lehman Brothers and remained larger than before. The interaction terms show that there is a significant relative decrease of $R_{t}$ for financials in these periods.

The next section in Table 5 shows the results for the relative bid-ask spread $B A_{t, r e l}^{\text {def }}$. There is a strongly negative relation between $B A_{t, r e l}^{\text {def }}$ and the default premium. Overall, financials have a significantly higher relative bid-ask spread than non-financials. While the relative bid-ask spread decreased substantially after the start of the crisis, it decreased even more for financials, eventually leading to a lower spread than non-financials. All coefficients are highly significant.

The fourth and fifth regressions in Table 5 show the results for two variables, obtained by using our model to decompose the relative bid-ask spread $B A_{t, r e l}^{\text {def }}$ into its two components, relative ask liquidity premium $S L_{t, r e l}^{a s k}$ and relative bid liquidity premium $S L_{t, r e l}^{b i d}$. While the relative bid liquidity premium can be explained very well by the regression, the goodness of fit is very low for the relative ask liquidity premium. It can be seen that the decrease of the relative bid-ask spread as discussed before can be attributed to the bid premium rather than the ask premium. 
The last regression relates the difference between mid quotes and model-implied CDS values $\left(\Delta S_{t}\right)$ to the explanatory variables. The highly significant constant of -0.8968 shows that on average, the model-implied default spread is higher than the mid quote. The coefficient for financials has a value of 0.2566 and is significantly positive, implying that the difference between mid quotes and model spreads is lower for financials than non-financials during the pre-crisis period, but it is still negative. The dummy variables for the periods indicate that for non-financials, the error increases in the subprime and recovery periods, while it decreases in the systemic and sovereign periods. In all periods, mid-quotes remain lower than model spreads. The interaction terms all have negative signs and are highly significant, implying that the error $\Delta S_{t}$ for financials is even higher than for non-financials during the crisis periods. Overall, we find that mid-quotes very consistently underestimate the true default risk for all periods and for both financials and non-financials. The highest errors can be observed for financials during the crisis.

\subsubsection{Liquidity Regimes}

The juxtaposition of the CDS default premia and the ask liquidity proportion reveals three regimes. A CDS market regime of low default risk and low ask liquidity proportion which occurs during the pre-crisis period. During this period, the average CDS default spread is about $34.37 \mathrm{bps}$ and the ask liquidity proportion is on average equal to $25.71 \%$. As documented in Section 3, the outstanding notional amount continuously increases, the large demand and supply of protection leads to lower ask liquidity proportion in a low default risk environment.

The second regime occurs during the next period, the subprime phase, and also during the recovery phase. The second regime is given as a state in which credit markets exhibit a substantial default risk but remain liquid. The subprime phase is characterized by a growing CDS default premium (70.12 bps on average), but a lower average ask liquidity proportion $23.50 \%$. During this period, investors are not reluctant to sell protection, although the credit quality of many obligors is deteriorating and the demand for insurance against the rising default risk is increasing. This is consistent with the ISDA survey (see Section 3) that reports a peak of the outstanding notional amount during the second half of 2007 which coincides with the subprime phase. Moreover, the low liquidity proportion of protection sellers during a period of large default risk seems to be theoretically supported 
by a stabilizing margin spiral as presented in Brunnermeier and Pedersen (2009). During the recovery phase, we observe a diminishing CDS default premium and relatively low ask liquidity proportion. Since the beginning of the crisis, during the subprime and systemic phases, governments intervene by introducing numerous policy rules and by providing enough liquidity (funding) in order to ease the trades in financial markets. These measures actually succeed during the recovery phase not only in stabilizing the jumpy market as shown by Acharya, Drechsler, and Schnabl (2010) and facilitating financing conditions, but also to improve confidence among financiers. Thus, investors believe in a more favorable economic outlook and can easily access liquid assets; they therefore supply more CDS contracts to the rising demand of protection. Compared to the previous systemic phase, this yields a lower ask liquidity proportion with an average of $32.10 \%$.

The third regime is the worst state, where default risk and the liquidity proportion deteriorate. The third regime is found in the systemic phase and in the sovereign phase. During the systemic phase, the Libor-Ois spread significantly rises, the CBOE VIX peaks and most equity indices plummet. During this period, the CDS default premium also peaks and the ask liquidity proportion relatively to the previous subprime phase also doubles to $41.7 \%$. Thus, in this period of fragile financial markets, with weak funding conditions, high risk aversion and high credit risk, investors are less confident, less optimistic and shy away from risky assets. Thus, they supply less CDS contracts which leads to an increase of the ask liquidity proportion and a less liquid CDS market. During the sovereign phase, the credit quality of several European countries crumbles, leading to their downgrade. This casts doubt on the capacity of governments to stabilize the financial market and consequently, the confidence established during the previous recovery phase shrinks. Thus, investors are less inclined to sell insurance against increasing default risk and supply less protection. The ask liquidity proportion jumps to $43.8 \%$.

To our knowledge, we are the first to empirically report the impact of government guarantees on the liquidity requirement of protection sellers in CDS markets. The financial crisis was mainly a bank crisis, and most rescue measures, such as e.g. bail-outs, provision of guarantees for toxic assets, and stimulus packages, mostly concern financial institutions. The impact of government measures on the ask liquidity proportion can be gauged in Table 4 as comparison of the ask liquidity proportions of financials and non-financials. The ask liquidity proportion of financials is on average larger than that of non-financials, and 
the difference is larger during the systemic, recovery and sovereign phases. During the pre-crisis and the subprime phase, periods with smaller interlinkages between assets of financial institutions and sovereigns, the difference between both ask liquidity proportions is also small, with respectively $3.6 \%^{2}$ and $-0.1 \%$. As government interventions become effective, the gap increases to $13.9 \%$ during the systemic phase. But it is noticeable that the gap peaks at $25 \%$ during the recovery phase, when the ask liquidity proportions of financials and non-financials decline. During the systemic and the recovery phase, financiers expect governments to be able to discipline the banking system and to always provide guarantees against the default of financial institutions. Therefore, they become more optimistic and more confident of financial institutions than of non-financials. Thus, financiers are more willing to sell protection on financial institutions, and they thereby stronger reduce the ask liquidity proportion for financial institutions than for non-financial institutions. Thereafter, this gap shrinks to $16.2 \%$ during the sovereign phase, although the liquidity proportions and CDS default premia of both institutions climb. Given the sovereign crisis, protection sellers are less confident of governments to solve the banking crisis and less optimistic about CDS of financial institutions than before. They increase more significantly the ask liquidity proportion of financials, narrowing the gap to nonfinancials. The large gap of ask liquidity proportion between financials and non-financials in the last three phases compared to the first and second phase can be explained by the increasing bailout probability.

In this section, we uncover three main regimes. The first regime, occurring during the pre-crisis period, is a regime of liquid markets with low default risk. The second regime, observable during the subprime and recovery phases, is a regime of liquid markets with high default risk. The third regime, present in the systemic and sovereign phases, is a state of illiquid markets with high default risk. We believe there exists a fourth regime of an illiquid market with low default risk. This regime can apply to the CDS market in its beginning period. We are also pioneers in revealing the impact of government interventions on the protection sellers' liquidity premium requirement on CDS contracts of financials and non-financials.

\footnotetext{
$23.6 \%$ is the difference between the non-financial ask liquidity proportion $26.4 \%$ and the financial ask liquidity proportion $22.8 \%$ reported in Table 4
} 


\section{Conclusion}

Our main objective in this paper is to estimate the CDS default risk and the liquidity premium from CDS bid and ask quotes. In order to better analyze the asymmetry in the liquidity premium of the protection buyer and seller, we introduce the ask liquidity proportion of the protection seller, defined as the ratio of the ask liquidity premium to the bid-ask spread. Moreover, we split our data in five periods that relate to distinct market conditions: the pre-crisis phase, January 2004 - July 2007, characterized by a steady decline in CDS prices with a lower volatility; the subprime phase, August 2007 - August 2008, determined by the subprime credit crisis; the systemic phase, September 2008 March 2009, catalyzed by the bankruptcy of Lehman Brothers and defined by a severe worsening of credit and liquidity conditions as well as larger market volatility; the recovery phase from April 2009 - December 2009, where CDS mid quotes fall and the market is less volatile; and as a last period the sovereign phase from January - September 2010, characterized by widening CDS spreads and growing sovereign risk. We investigate the properties and the determinants of the liquidity premia under different market conditions.

Using a state-space model on the log-prices of 118 CDS, we find that the default premium and the liquidity premium are strongly interconnected, especially from the beginning of the financial turbulence. During periods of large default premia, such as the systemic and sovereign phase, the ask liquidity proportion rises. Thus, the correlation between the default and liquidity variables should not be ignored when pricing CDS contracts. Moreover, CDS mid quotes cannot be a pure measure of default risk since we find that for most names, the bid liquidity premium is larger than the ask liquidity premium, i.e. the protection buyer receives a larger liquidity premium than the protection seller. We find that different phases of the financial crisis affect both, the default premium and the liquidity premia earned by protection buyers and sellers. These effects are not symmetrical, and they are different for financial names compared to non-financial names. Moreover, the comparison of default premia and ask liquidity proportions reveals three regimes that are present in different phases of the financial crisis. Overall, the obtained results demonstrate the necessity of applying a fully specified model to obtain robust estimates for true default premia and liquidity premia. 


\section{References}

Acharya, V. V., I. Drechsler, and P. Schnabl (2010). A pyrrhic victory? bank bailouts and sovereign credit risk. Working paper, Stern School of business.

Acharya, V. V. and L. H. Pedersen (2005). Asset pricing with liquidity risk. Journal of Financial Economics 77, 375-410.

Amihud, Y. and H. Mendelson (1988). Dealership market-making with inventory. Journal of Finance 8, 31-53.

Arora, N., P. Gandhi, and F. Longstaff (2012). Counterparty credit risk and the credit default swap market. Journal of Financial Economics 103, 280 - 293.

Bakshi, G., D. Madan, and F. Zhang (2006). Understanding the role of recovery in default risk models: empirical comparison and implied recovery rates. Working paper, University of Maryland.

Bongaerts, D., F. de Jong, and J. Driessen (2011). Derivatives pricing with liquidity risk: Theory and evidence from the credit default swap market. Journal of Finance 66, 203 $-240$.

Brunnermeier, M. and L. Pedersen (2009). Market liquidity and funding liquidity. Review of Financial Studies 22, 2201-2238.

Bühler, W. and M. Trapp (2010). Time-varying credit risk and liquidity premia in bond and cds markets. Working paper, University of Mannheim.

Caceres, C., V. Guzzo, and M. Segoviano (2010). Sovereign spreads: Global risk aversion, contagion or fundamentals? IMF Working paper.

Chen, R.-R., F. Fabozzi, and R. Sverdlove (2010). Corporate credit default swap liquidity and its implications for corporate bond spreads. The Journal of Fixed Income 20, 31 57.

Conrad, J., R. Dittmar, and A. Hameed (2011). Cross-market and cross firm effects in implied default probabilities and recovery values. Working paper, University of North Carolina. 
Das, S. and P. Hanouna (2009). Implied recovery. Journal of Economic Dynamics and Control 33, $1837-1857$.

Dick-Nielsen, J., P. Feldhütter, and D. Lando (2011). Corporate bond liquidity before and after the onset of the subprime crisis. Working paper, Copenhagen Business School.

Fulop, A. and L. Lescourret (2009). Intra-daily variations in volatility and transaction costs in the credit default swap market. Working paper, ESSEC Business School.

Hasbrouck, J. (1999). The dynamics of discrete bid and ask quotes. Journal of Finance 54, $2109-2142$.

Kim, C.-J. and C. Nelson (1999). State space models with regime switching. MIT Press.

Longstaff, F., S. Mithal, and E. Neis (2005). Corporate yield spreads: Default risk or liquidity? new evidence from the credit-default swap market. Journal of Finance 60, $2213-2254$.

Panetta, F., R. Correa, M. Davies, A. D. Cesare, J. M. Marques, F. N. de Simone, F. Signoretti, C. Vespro, S. Vildo, M. Wieland, and A. Zaghini (2011). The impact of sovereign credit risk on bank funding conditions. CGFS Working paper, 43.

Schlaefer, T. and M. Uhrig-Homburg (2010). Estimating market implied recovery rates from credit default swap premia. Working paper, Karlsruhe Institute of Technology.

Schneider, P., L. Soegner, and T. Veza (2010). The economic role of jumps and recovery rates in the market for corporate default risk. Journal of Financial and Quantitative Analysis 6, $1517-1547$.

Simon, D. (2006). Optimal state estimate: Kalman, H infinity, and nonlinear approaches. John Wiley and Sons.

Tang, D. Y. and H. Yan (2007). Liquidity and credit default swap spreads. Working paper, Imperial college London.

van Emmerich, C. (2006). Modelling correlation as a stochastic process. Working paper, Bergische Universität Wuppertal. 
6 Figures 
Figure 1: Time-series of CDS mid quotes, bid-ask spreads, and relative bid-ask spreads

This figure depicts time-series of averaged CDS mid quotes $S_{t}^{\text {mid }}$, bid-ask spreads $B A_{t}$, and relative bid-ask spreads $B A_{t, r e l}^{\text {mid }}$ for the financial and non-financial sector. $B A_{t, r e l}^{\text {mid }}$ is calculated as the ratio of bid-ask spreads to the mid quotes. The average is taken over individual names. The vertical lines indicate different periods.

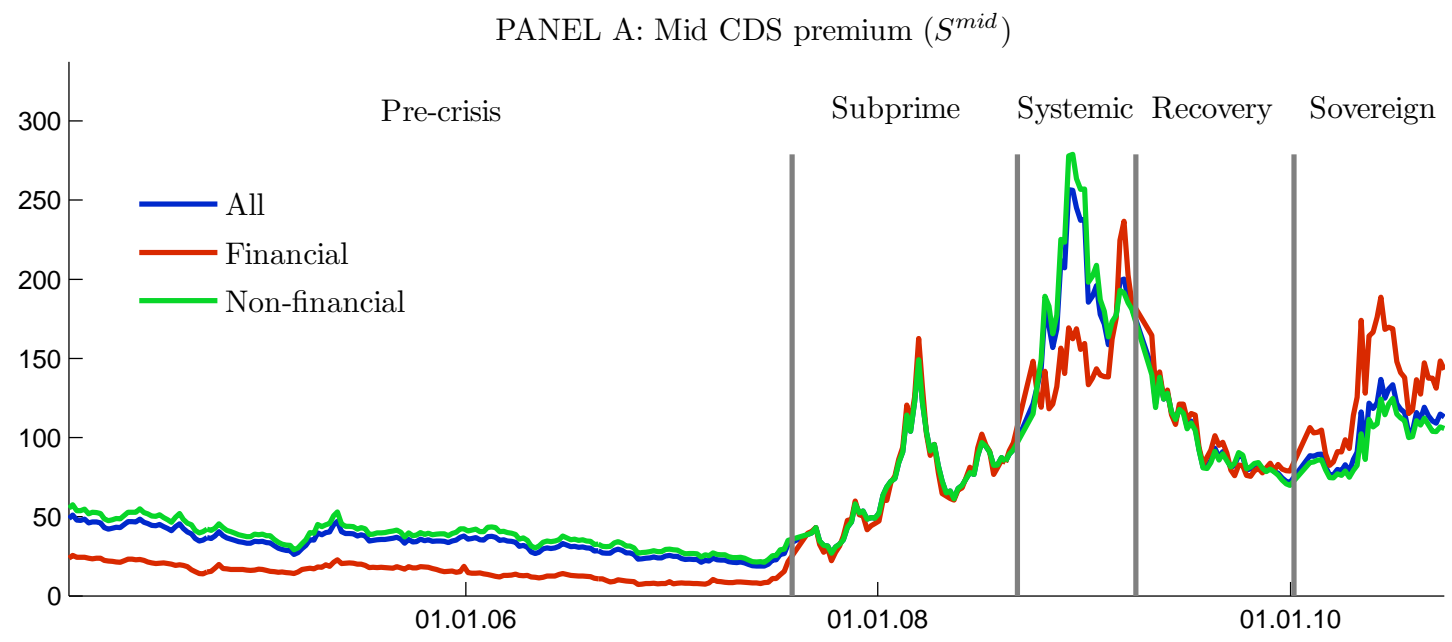

PANEL B: Bid-ask spread $(B A)$

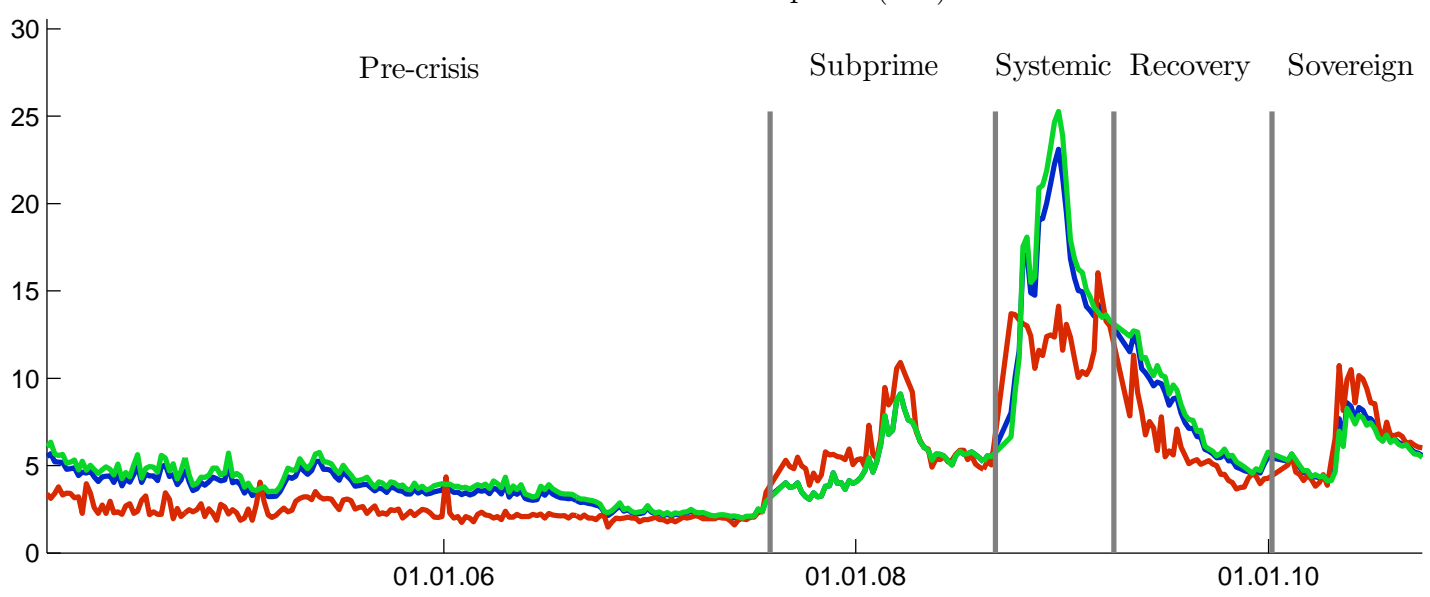

PANEL C: Bid-ask spread relative to mid quote $\left(B A_{\text {rel }}^{\text {mid }}\right)$

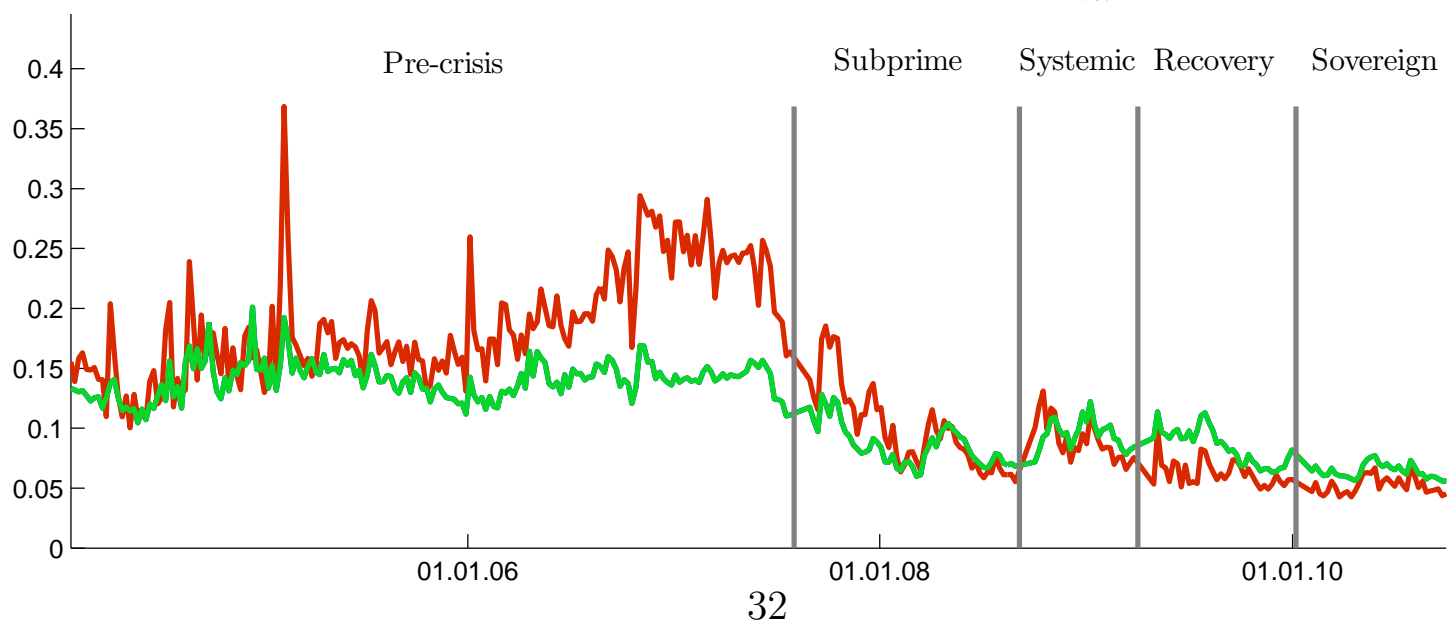


Figure 2: Time-series of the model-implied CDS premium, ask and bid liquidity premia

This figure depicts time-series of averaged model-implied CDS premia $S_{t}^{\text {def }}$, ask $S L_{t}^{\text {ask }}$ and bid $S L_{t}^{\text {bid }}$ liquidity premia for the financial and non-financial sector. The average is taken over individual names. The vertical lines indicate different periods.

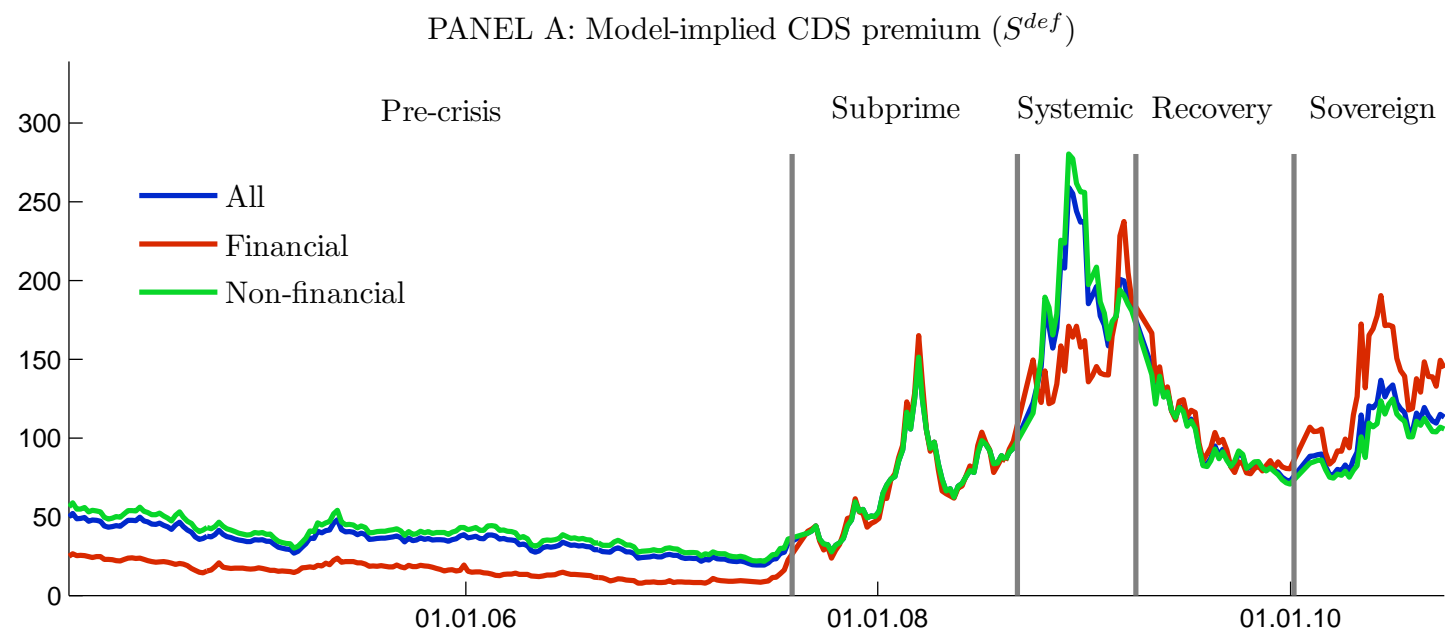

PANEL B: Ask liquidity premium $\left(S L^{a s k}\right)$

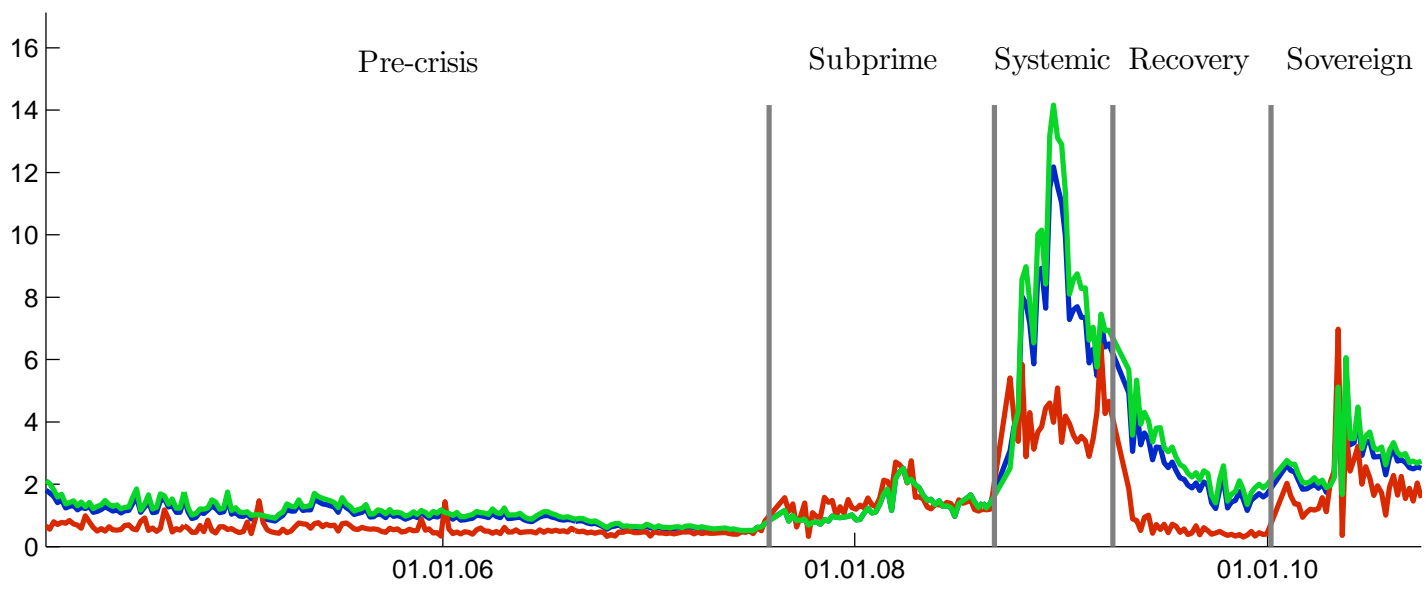

PANEL C: Bid liquidity premium $\left(S L^{b i d}\right)$

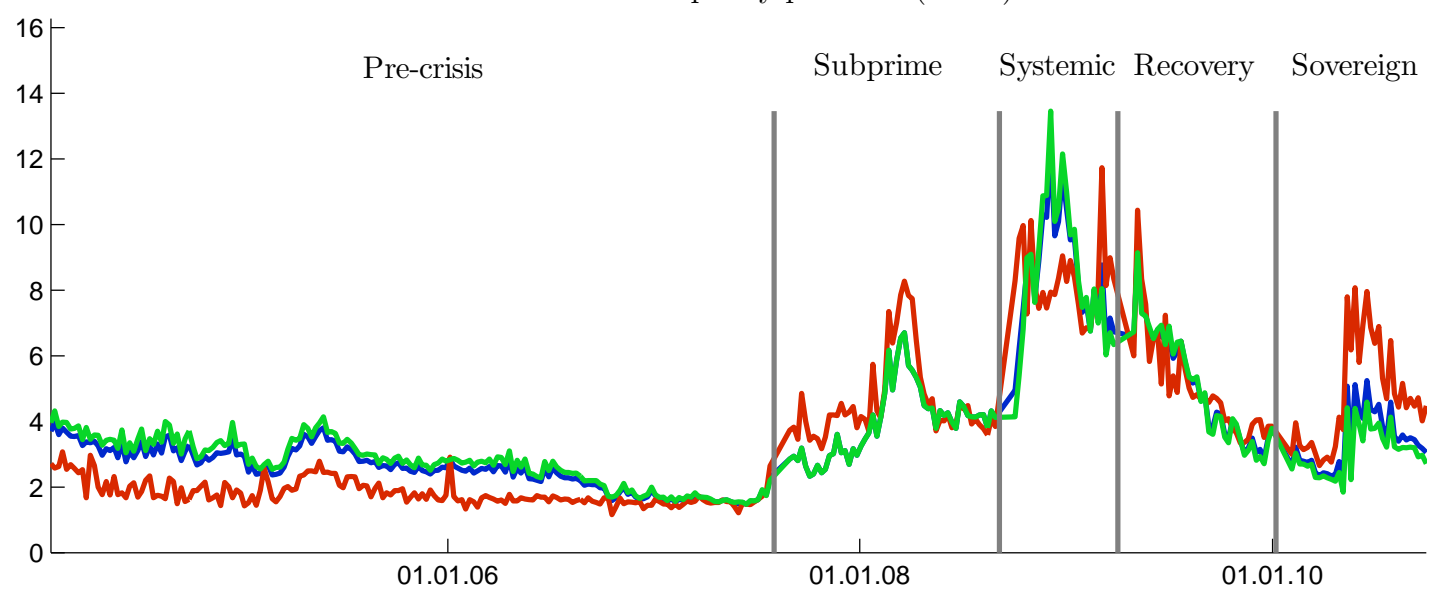


Figure 3: Time-series of the relative bid-ask spread and, ask and bid liquidity premia

This figure depicts time-series of the relative bid-ask spread $B A_{t, r e l}^{\text {def }}$, the relative ask $S L_{t, r e l}^{a s k}$ and bid $S L_{t, r e l}^{b i d}$ liquidity premia for the financial and non-financial sector. They are computed relatively to the model default premia. The average is taken over individual names. The vertical lines indicate different periods.
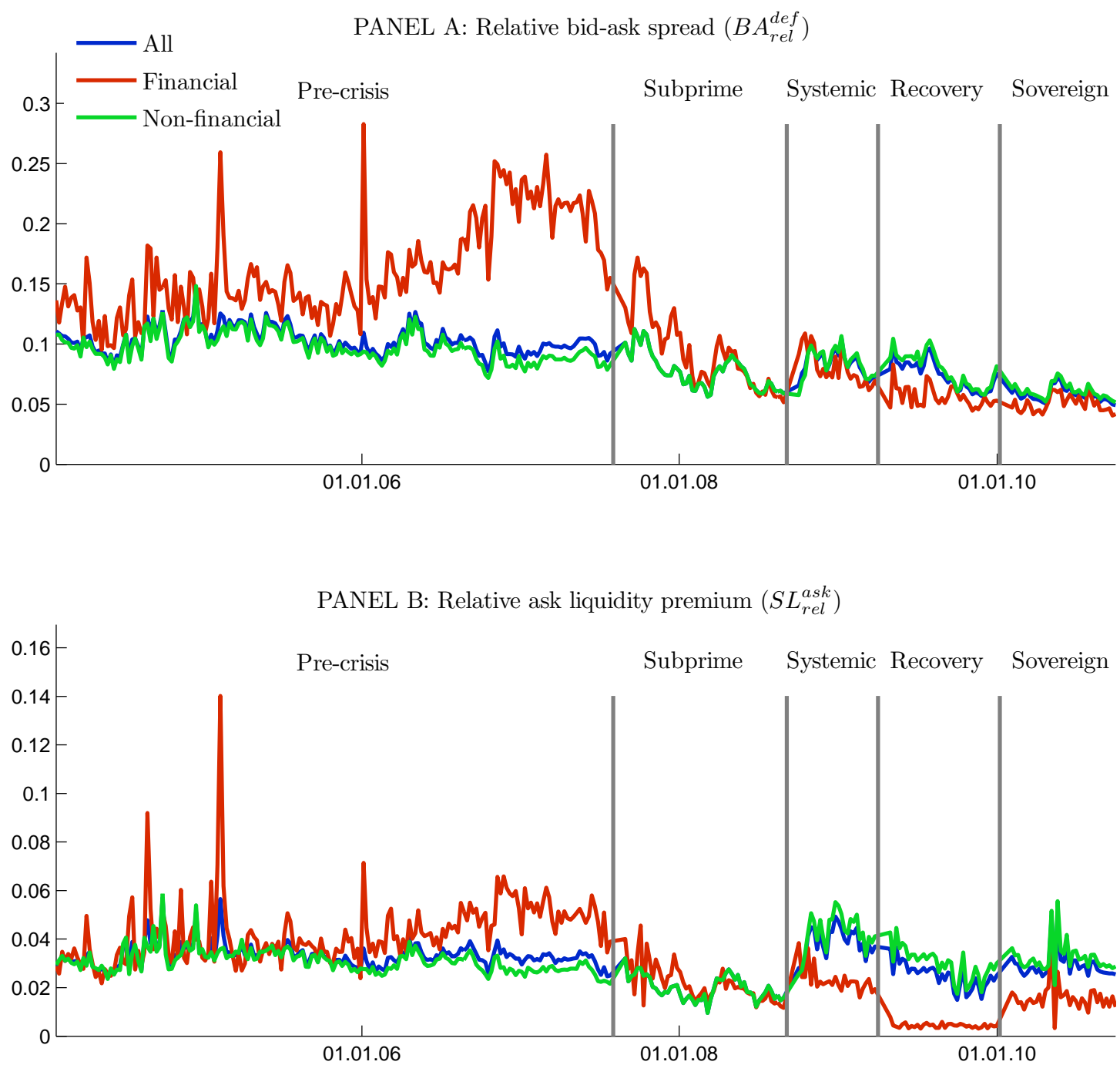

PANEL C: Relative bid liquidity premium $\left(S L_{r e l}^{b i d}\right)$

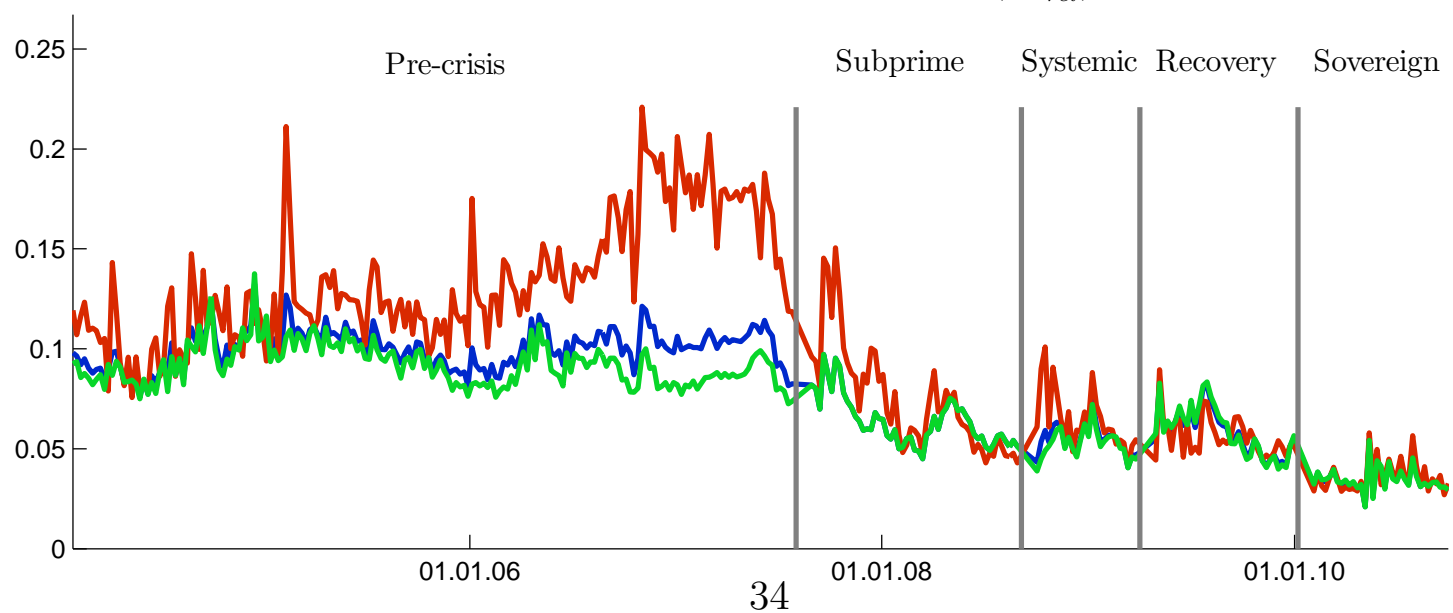


Figure 4: Time-series of the proportional ask liquidity premia and the deviation of the mid quotes from the model-implied CDS premia

This figure depicts time-series of the averaged proportional ask liquidity premia $R_{t}$ and of the difference between the mid quotes and the model-implied CDS premia $\Delta S_{t}=$ $S_{t}^{\text {mid }}-S_{t}^{\text {def }}$. The average is taken over individual names. The vertical lines indicate different periods.

PANEL A: Ask liquidity proportion $(R)$

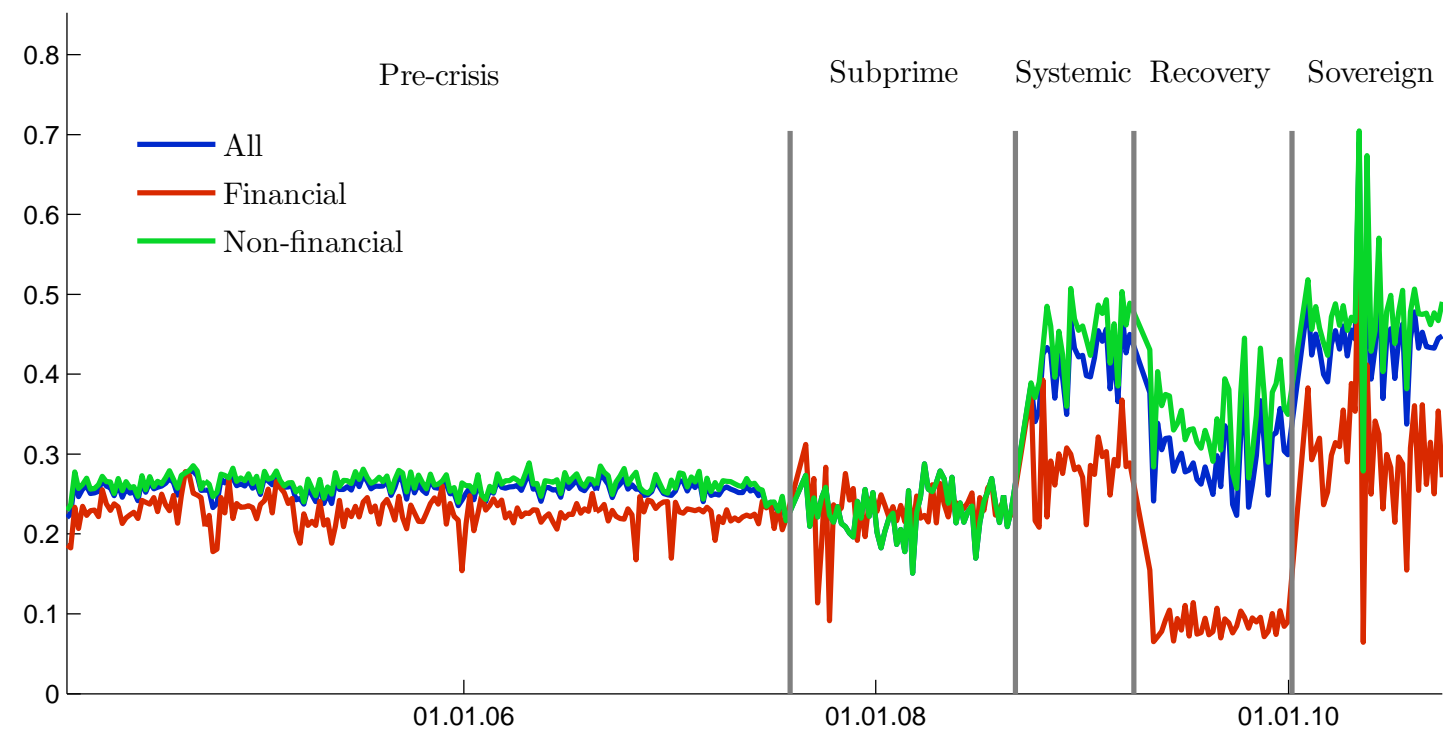

PANEL B: Deviation of mid from fair CDS premium $(\Delta S)$

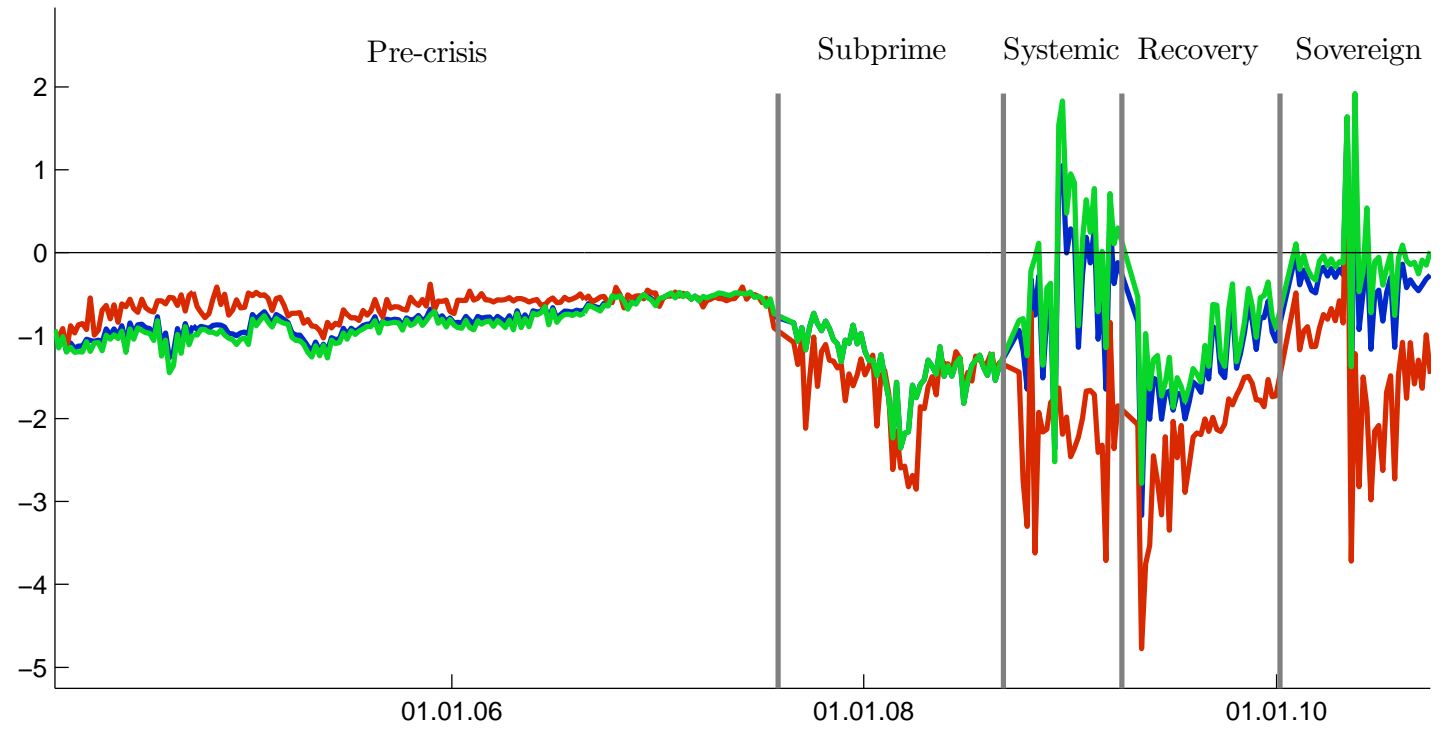


Figure 5: Histogram of the model-implied CDS premium $S_{t}^{\text {def }}$

This figure depicts the distribution of the model-implied CDS premium $S_{t}^{\text {def }}$ for the financial and non-financial sector and also exhibits its evolution over different periods, from the pre-crisis period over different phases of the financial crisis.

Model-implied CDS premium $\left(S^{\text {def }}\right)$
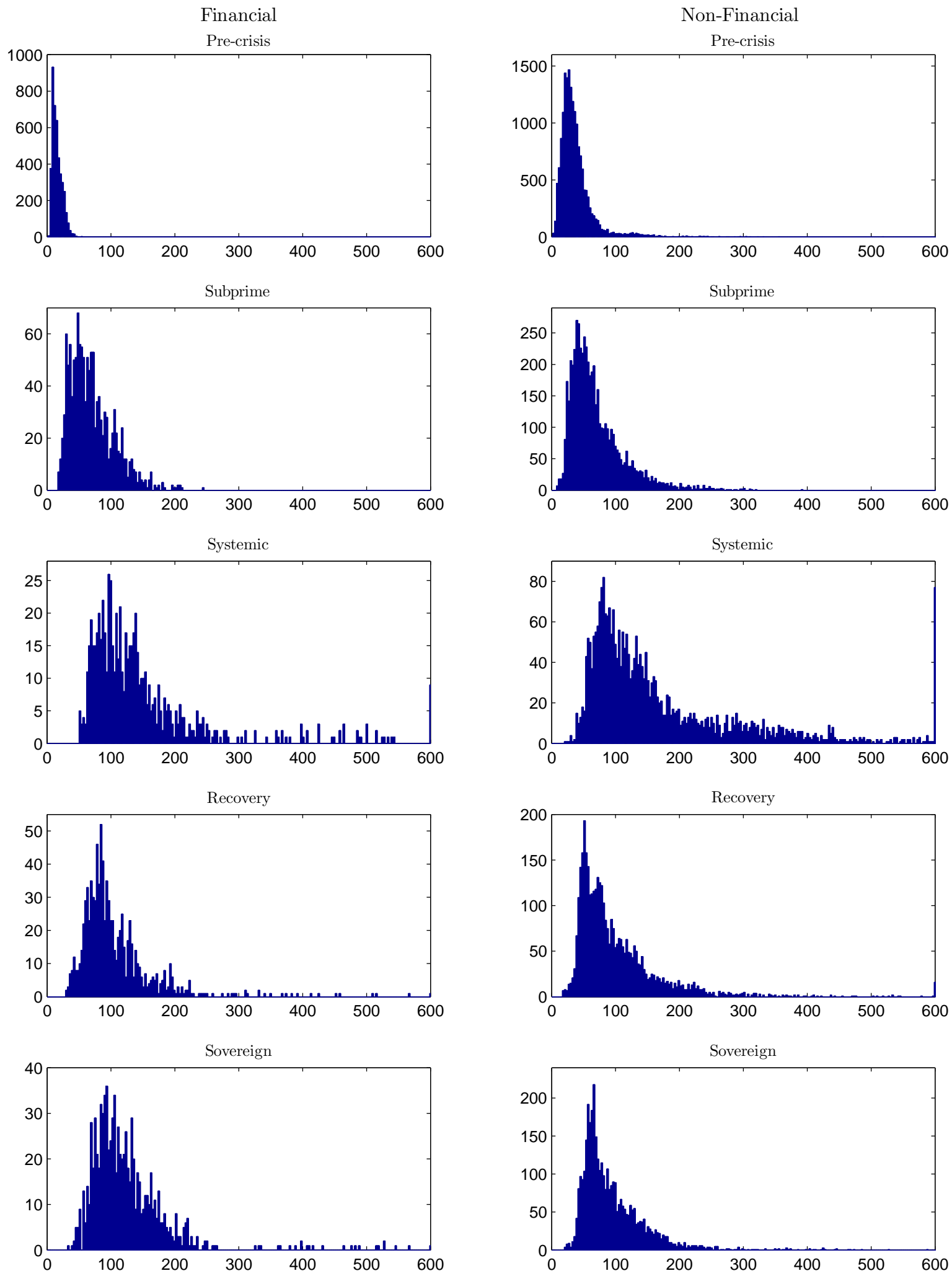
Figure 6: Histogram of the relative bid-ask spread

This figure depicts the distribution of the relative bid ask spread $B A_{t, r e l}^{d e f}=\frac{B A_{t}}{S_{t}^{\text {def }}}$ for the financial and non-financial sector and also exhibits its evolution over different periods, from the pre-crisis period over different phases of the financial crisis.

Relative bid-ask spread $\left(B A_{r e l}^{\text {def }}\right)$
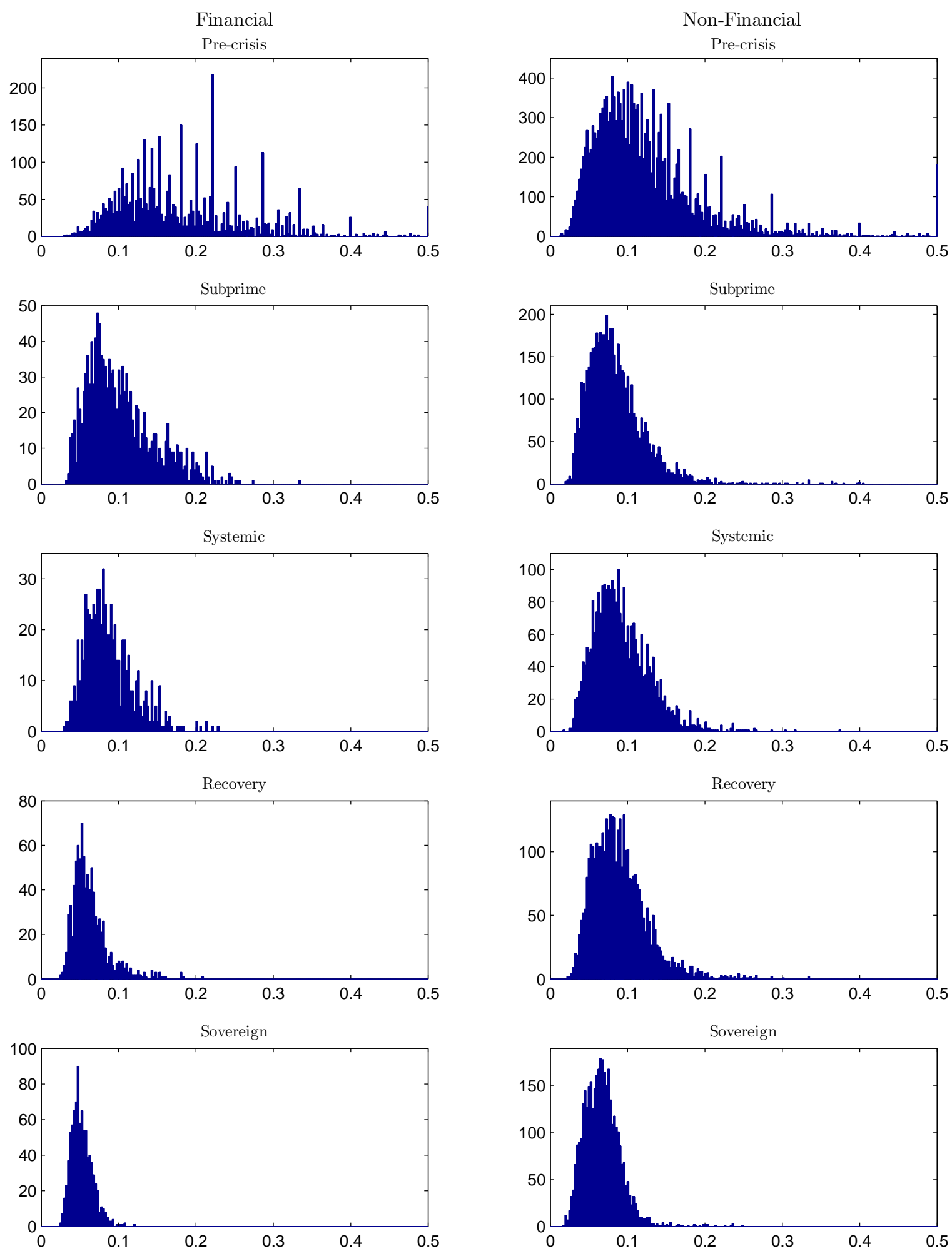
Figure 7: Histogram of the relative liquidity premium of the protection buyer

This figure depicts the distribution of the relative liquidity premium of the protection buyer $S L_{t, r e l}^{\text {bid }}=\frac{S L_{t}^{\text {bid }}}{S_{t}^{\text {def }}}$ for the financial and non-financial sector and also exhibits its evolution over different periods, from the pre-crisis period over different phases of the financial crisis.

Relative bid liquidity premium $\left(S L_{r e l}^{b i d}\right)$
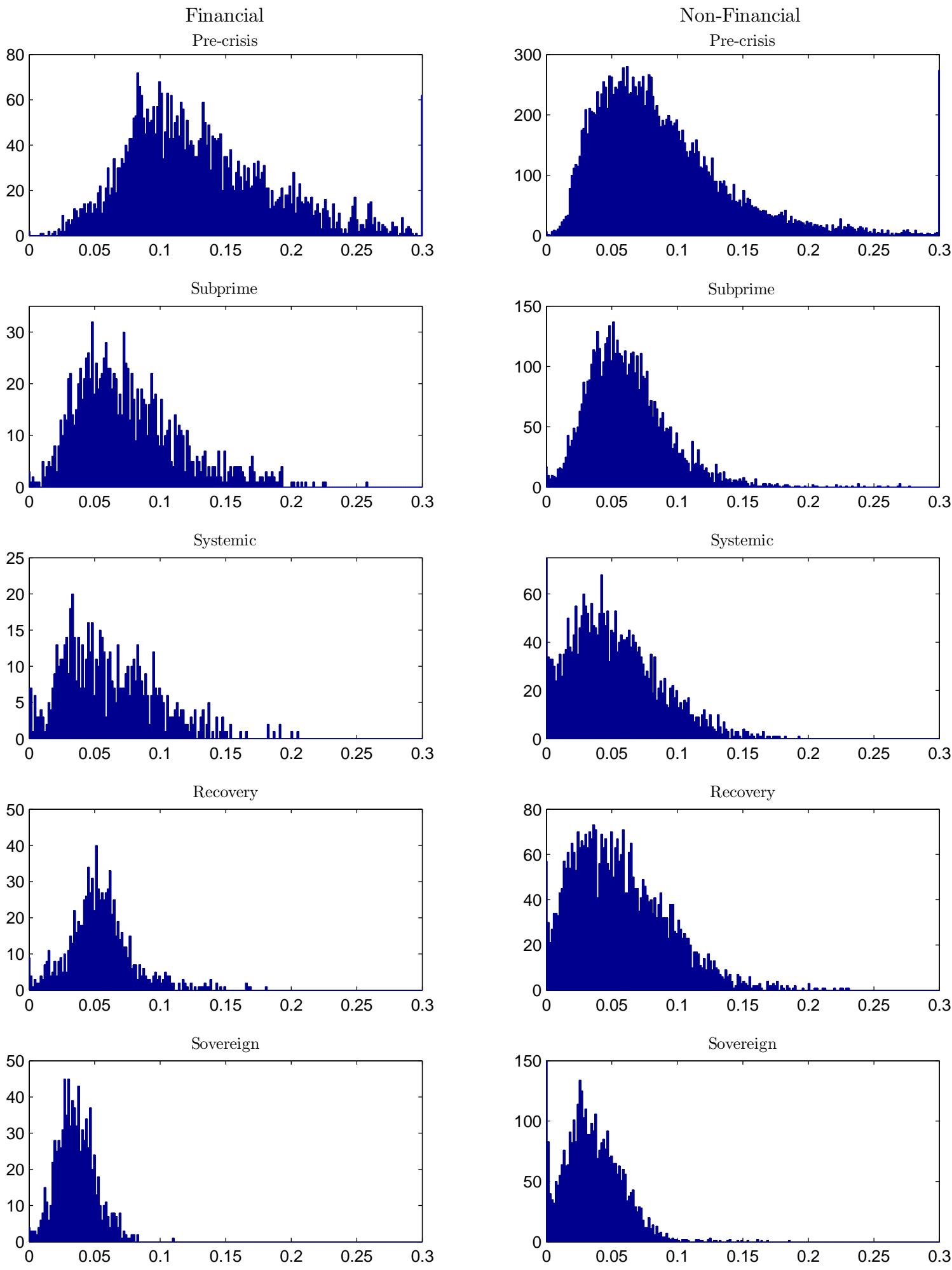
Figure 8: Histogram of the relative liquidity premium of the protection seller

This figure depicts the distribution of the relative liquidity premium of the protection seller $S L_{t, r e l}^{a s k}=\frac{S L_{t}^{a s k}}{S_{t}^{\text {def }}}$ for the financial and non-financial sector and also exhibits its evolution over different periods, from the pre-crisis period over different phases of the financial crisis.

Relative ask liquidity premium $\left(S L_{r e l}^{a s k}\right)$
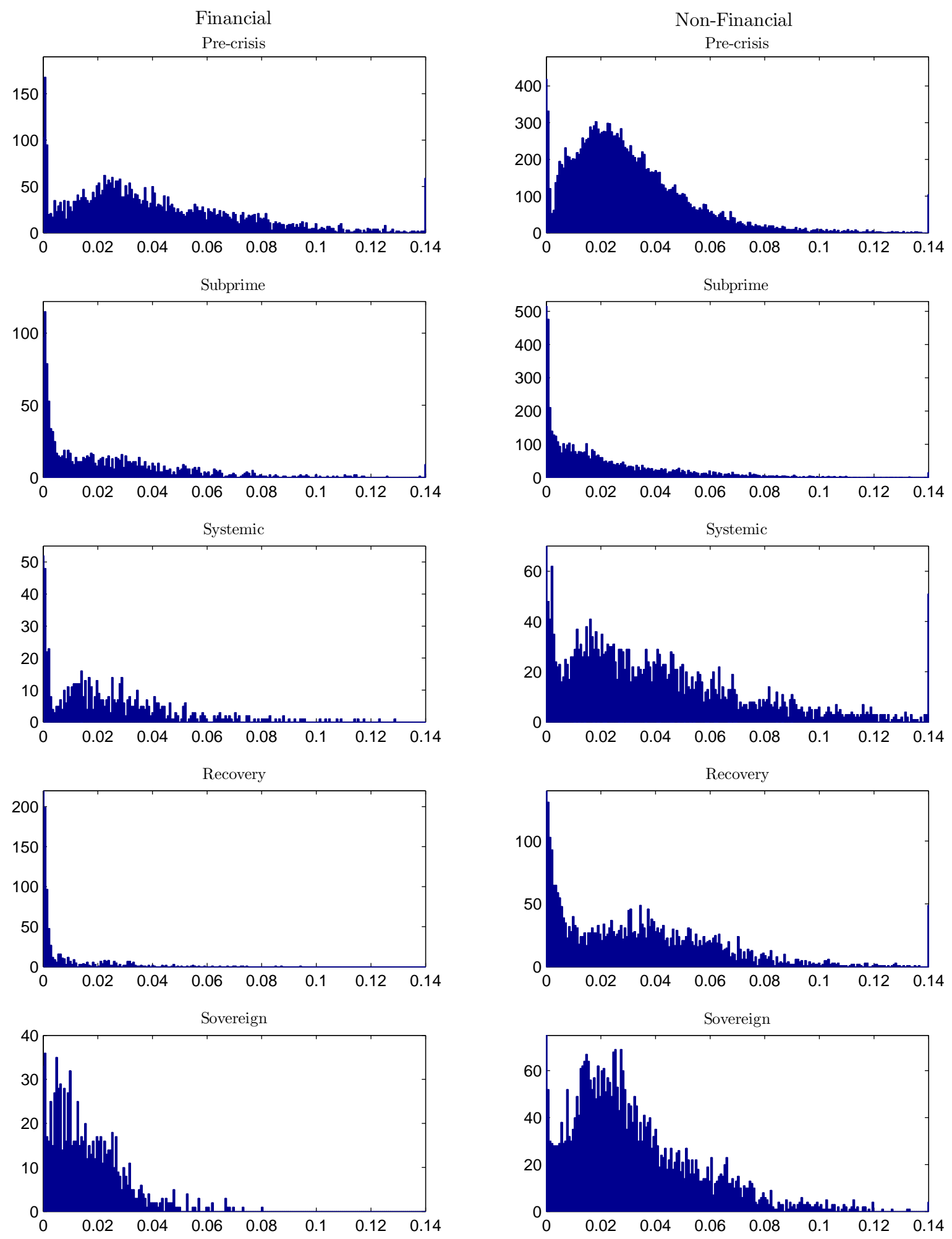
Figure 9: Histogram of the ask liquidity premium proportional to the bid-ask spread

This figure depicts the distribution of the liquidity premium of the protection seller proportional to the bid-ask spread $R_{t}=\frac{S L_{t}^{a s k}}{B A_{t}}$ for the financial and non-financial sector and also exhibits its evolution over different periods, from the pre-crisis period over different phases of the financial crisis.

Ask liquidity proportion $(R)$
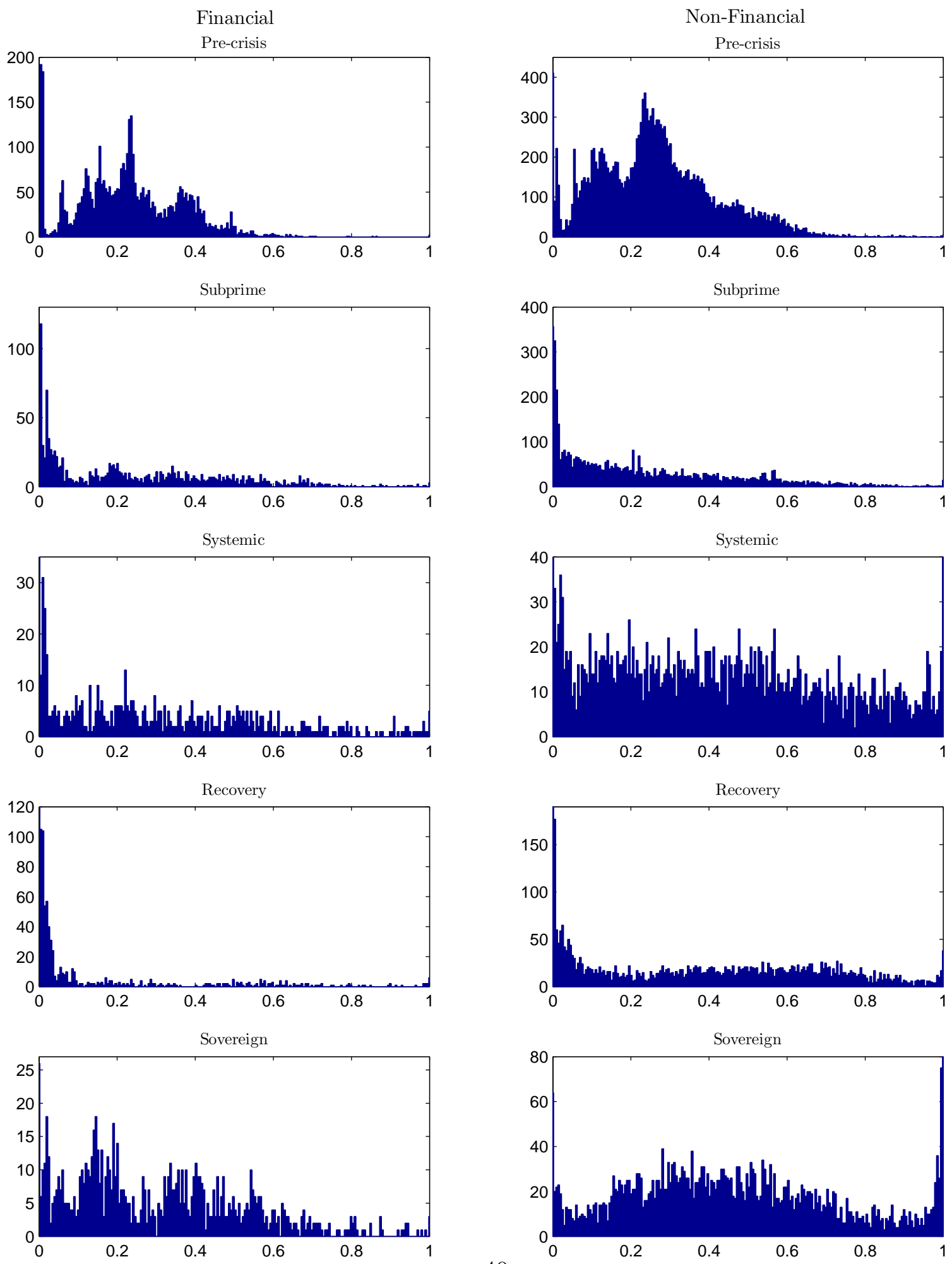
Figure 10: Histogram of the deviation of the mid quotes from the model-implied CDS premia

This figure depicts the distribution of the difference between the mid quotes and the model-implied CDS premia $\Delta S_{t}=S_{t}^{\text {mid }}-S_{t}^{\text {def }}$ for the financial and non-financial sector and also exhibits its evolution over different periods, from the pre-crisis period over different phases of the financial crisis.

Difference between mid quotes and model-implied CDS premia $(\Delta S)$
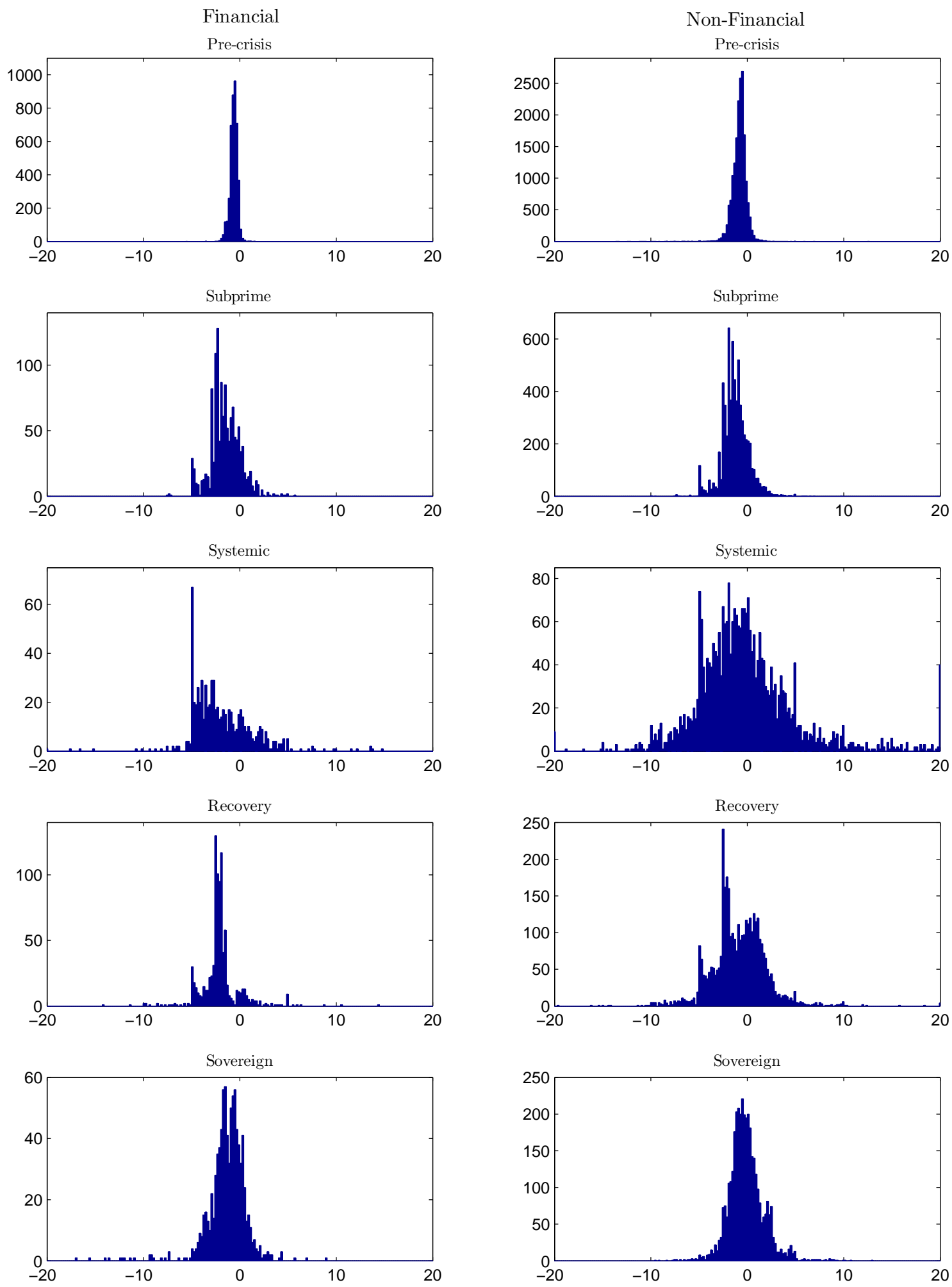
$\begin{array}{ll}7 & \text { Tables }\end{array}$ 


\section{Table 1: Summary Statistics}

This table reports the means, the minimums, the maximums, the medians and standard deviations (std) of the collected data. $S_{t}^{\text {mid }}$ is the CDS mid premium. $B A_{t}$ is the absolute bid-ask spread. $B A_{t, r e l}^{\text {mid }}$ is the relative bid-ask spread computed as the ratio of the bid-ask spread to the mid premium. $\rho_{\text {mid }}$ denotes the empirical correlation between the CDS mid premium and a corresponding variable (absolute bid-ask spread or relative bid-ask spread).

\begin{tabular}{|c|c|c|c|c|c|c|c|c|c|}
\hline & \multicolumn{3}{|c|}{ ALL } & \multicolumn{3}{|c|}{ NON-FINANCIALS } & \multicolumn{3}{|c|}{ FINANCIALS } \\
\hline & \multicolumn{9}{|c|}{$\begin{array}{c}\text { Pre-crisis Phase } \\
\text { January } 2004 \text { - July } 2007\end{array}$} \\
\hline & $S_{t}^{\text {mid }}$ & $B A_{t}$ & $B A_{t, \text { rel }}^{\text {mid }}$ & $S_{t}^{\text {mid }}$ & $B A_{t}$ & $B A_{t, r e l}^{\text {mid }}$ & $S_{t}^{\text {mid }}$ & $B A_{t}$ & $B A_{t, r e l}^{\text {mid }}$ \\
\hline mean & 33.570 & 3.556 & 0.140 & 38.075 & 3.840 & 0.129 & 15.211 & 2.398 & 0.186 \\
\hline $\min$ & 3.000 & 1.000 & 0.012 & 3.000 & 1.000 & 0.012 & 3.500 & 1.000 & 0.030 \\
\hline $\max$ & 528.300 & 82.000 & 1.985 & 528.300 & 82.000 & 1.985 & 58.500 & 48.000 & 1.983 \\
\hline median & 26.800 & 3.000 & 0.118 & 30.700 & 3.000 & 0.109 & 13.500 & 2.000 & 0.166 \\
\hline std & 31.189 & 2.997 & 0.107 & 33.086 & 3.209 & 0.102 & 7.491 & 1.395 & 0.116 \\
\hline \multirow[t]{3}{*}{$\rho_{\text {mid }}$} & 1.000 & 0.590 & -0.347 & 1.000 & 0.579 & -0.321 & 1.000 & 0.271 & -0.492 \\
\hline & \multicolumn{9}{|c|}{$\begin{array}{c}\text { Subprime Phase } \\
\text { August } 2007 \text { - August } 2008\end{array}$} \\
\hline & $S_{t}^{\text {mid }}$ & $B A_{t}$ & $B A_{t, \text { rel }}^{\text {mid }}$ & $S_{t}^{\text {mid }}$ & $B A_{t}$ & $B A_{t, \text { rel }}^{\text {mid }}$ & $S_{t}^{\text {mid }}$ & $B A_{t}$ & $B A_{t, r e l}^{\text {mid }}$ \\
\hline mean & 68.824 & 5.207 & 0.089 & 68.912 & 5.010 & 0.085 & 68.307 & 6.004 & 0.103 \\
\hline $\min$ & 8.500 & 1.000 & 0.020 & 8.500 & 2.000 & 0.020 & 0.000 & 0.000 & 0.034 \\
\hline $\max$ & 390.000 & 25.000 & 0.404 & 390.000 & 25.000 & 0.404 & 244.200 & 20.000 & 0.333 \\
\hline median & 57.700 & 5.000 & 0.080 & 57.100 & 5.000 & 0.078 & 61.450 & 5.000 & 0.093 \\
\hline std & 41.592 & 2.426 & 0.041 & 43.134 & 2.443 & 0.039 & 34.629 & 2.192 & 0.045 \\
\hline$\rho_{\text {mid }}$ & 1.000 & 0.690 & -0.524 & 1.000 & 0.717 & -0.506 & 1.000 & 0.606 & -0.672 \\
\hline
\end{tabular}

Systemic Phase

September 2008 - March 2009

\begin{tabular}{|c|c|c|c|c|c|c|c|c|c|}
\hline & $S_{t}^{\text {mid }}$ & $B A_{t}$ & $B A_{t, \text { rel }}^{\text {mid }}$ & $S_{t}^{m i d}$ & $B A_{t}$ & $B A_{t, \text { rel }}^{\text {mid }}$ & $S_{t}^{\text {mid }}$ & $B A_{t}$ & $B A_{t, r e l}^{\text {mid }}$ \\
\hline mean & 178.218 & 14.827 & 0.092 & 184.947 & 15.547 & 0.093 & 150.424 & 11.849 & 0.088 \\
\hline $\min$ & 23.200 & 3.000 & 0.017 & 23.200 & 3.000 & 0.017 & 45.000 & 4.000 & 0.029 \\
\hline $\max$ & 2915.600 & 310.000 & 0.374 & 2915.600 & 310.000 & 0.374 & 775.000 & 58.000 & 0.229 \\
\hline median & 125.000 & 10.000 & 0.086 & 127.500 & 10.000 & 0.087 & 120.000 & 10.000 & 0.082 \\
\hline std & 182.795 & 16.031 & 0.036 & 196.081 & 17.384 & 0.037 & 108.109 & 7.705 & 0.032 \\
\hline \multirow[t]{3}{*}{$\rho_{\text {mid }}$} & 1.000 & 0.891 & -0.227 & 1.000 & 0.895 & -0.215 & 1.000 & 0.839 & -0.399 \\
\hline & \multicolumn{9}{|c|}{$\begin{array}{cl} & \text { Recovery Phase } \\
\text { April } 2009 \text { - December } 2009\end{array}$} \\
\hline & $S_{t}^{\text {mid }}$ & $B A_{t}$ & $B A_{t, \text { rel }}^{\text {mid }}$ & $S_{t}^{\text {mid }}$ & $B A_{t}$ & $B A_{t, \text { rel }}^{\text {mid }}$ & $S_{t}^{\text {mid }}$ & $B A_{t}$ & $B A_{t, r e l}^{\text {mid }}$ \\
\hline mean & 102.472 & 7.845 & 0.085 & 101.722 & 8.236 & 0.090 & 105.565 & 6.232 & 0.064 \\
\hline $\min$ & 19.510 & 2.340 & 0.022 & 19.510 & 2.650 & 0.022 & 27.490 & 2.340 & 0.026 \\
\hline $\max$ & 1320.900 & 67.000 & 0.333 & 1320.900 & 67.000 & 0.333 & 635.380 & 40.000 & 0.208 \\
\hline median & 81.343 & 5.570 & 0.079 & 78.975 & 6.000 & 0.085 & 88.283 & 5.000 & 0.058 \\
\hline std & 77.933 & 5.272 & 0.036 & 81.130 & 5.530 & 0.036 & 62.979 & 3.613 & 0.024 \\
\hline$\rho_{\text {mid }}$ & 1.000 & 0.807 & -0.310 & 1.000 & 0.820 & -0.320 & 1.000 & 0.824 & -0.310 \\
\hline
\end{tabular}

Sovereign Phase

January 2010 - September 2010

\begin{tabular}{lrrr|rrr|rrr}
\hline & \multicolumn{1}{c}{$S_{t}^{\text {mid }}$} & \multicolumn{1}{c}{$B A_{t}$} & \multicolumn{1}{c}{$B A_{t, \text { rel }}^{\text {mid }}$} & \multicolumn{1}{c}{$S^{\text {mid }}$} & \multicolumn{1}{c}{$B A_{t}$} & \multicolumn{1}{c}{$B A_{t, \text { rel }}^{\text {mid }}$} & \multicolumn{1}{c}{$S_{t}^{\text {mid }}$} & \multicolumn{1}{c}{$B A_{t}$} & $B A_{t, \text { rel }}^{\text {mid }}$ \\
\cline { 2 - 9 } mean & 101.301 & 5.949 & 0.064 & 95.499 & 5.830 & 0.067 & 125.268 & 6.439 & 0.052 \\
min & 20.110 & 1.970 & 0.018 & 20.110 & 1.970 & 0.018 & 32.480 & 2.400 & 0.026 \\
max & 592.190 & 40.770 & 0.249 & 580.975 & 26.730 & 0.249 & 592.190 & 40.770 & 0.119 \\
median & 86.788 & 4.990 & 0.062 & 79.355 & 4.970 & 0.065 & 110.530 & 5.200 & 0.050 \\
std & 58.544 & 3.163 & 0.023 & 54.577 & 2.867 & 0.024 & 67.618 & 4.135 & 0.014 \\
$\rho_{\text {mid }}$ & 1.000 & 0.774 & -0.418 & 1.000 & 0.731 & -0.448 & 1.000 & 0.890 & -0.139 \\
\hline
\end{tabular}




\section{Table 2: Parameters estimates}

The estimates of the parameters of the $\log$-fair CDS premium $s_{t}=s_{t-1}+\eta_{t}$ and the liquidity process $r_{t}=\alpha+\beta r_{t-1}+\sqrt{\left(1-r_{r}\right) r_{t}} \epsilon_{t}$ are reported in this table.

\begin{tabular}{|c|c|c|c|c|c|c|c|c|c|c|c|c|c|c|c|}
\hline & \multicolumn{5}{|c|}{ ALL } & \multicolumn{5}{|c|}{ NON-FINANCIALS } & \multicolumn{5}{|c|}{ FINANCIALS } \\
\hline & \multicolumn{15}{|c|}{ Pre-crisis Phase: January 2004 - July 2007} \\
\hline & $\sigma_{\eta_{t}}$ & $\alpha$ & $\beta$ & $\sigma_{\epsilon_{t}}$ & $\rho_{\eta_{t}, \epsilon_{t}}$ & $\sigma_{\eta_{t}}$ & $\alpha$ & $\beta$ & $\sigma_{\epsilon_{t}}$ & $\rho_{\eta_{t}, \epsilon_{t}}$ & $\sigma_{\eta_{t}}$ & $\alpha$ & $\beta$ & $\sigma_{\epsilon_{t}}$ & $\rho_{\eta_{t}, \epsilon_{t}}$ \\
\hline mean & 0.0766 & 0.2066 & 0.1502 & 0.3482 & -0.4223 & 0.0749 & 0.2108 & 0.1709 & 0.3524 & -0.4204 & 0.0837 & 0.1891 & 0.0648 & 0.3308 & -0.4301 \\
\hline std & 0.0001 & 0.0024 & 0.0049 & 0.0024 & 0.0702 & 0.0001 & 0.0027 & 0.0052 & 0.0026 & 0.0719 & 0.0001 & 0.0009 & 0.0032 & 0.0006 & 0.0622 \\
\hline $\min$ & 0.0456 & 0.0003 & -0.8626 & 0.0001 & -1.0000 & 0.0456 & 0.0003 & -0.8626 & 0.0001 & -1.0000 & 0.0684 & 0.0024 & -0.7150 & 0.0045 & -0.9996 \\
\hline \multirow[t]{3}{*}{$\max$} & 0.1609 & 0.8764 & 0.9625 & 1.5916 & 1.0000 & 0.1609 & 0.8764 & 0.8813 & 1.5916 & 1.0000 & 0.1069 & 0.4599 & 0.9625 & 0.7557 & 0.9992 \\
\hline & \multicolumn{15}{|c|}{ Subprime Phase: August 2007 - August 2008} \\
\hline & $\sigma_{\eta_{t}}$ & $\alpha$ & $\beta$ & $\sigma_{\epsilon_{t}}$ & $\rho_{\eta_{t}, \epsilon_{t}}$ & $\sigma_{\eta_{t}}$ & $\alpha$ & $\beta$ & $\sigma_{\epsilon_{t}}$ & $\rho_{\eta_{t}, \epsilon_{t}}$ & $\sigma_{\eta_{t}}$ & $\alpha$ & $\beta$ & $\sigma_{\epsilon_{t}}$ & $\rho_{\eta_{t}, \epsilon_{t}}$ \\
\hline mean & 0.1323 & 0.2556 & 0.0729 & 0.6645 & -0.3832 & 0.1264 & 0.2558 & 0.0622 & 0.6314 & -0.4212 & 0.1566 & 0.2547 & 0.1168 & 0.8016 & -0.2263 \\
\hline std & 0.0003 & 0.0038 & 0.02 & 0.0026 & 0.0194 & 0.0003 & 0.0042 & 0.0172 & 0.0029 & 0.0210 & 0.0003 & 0.0004 & 0.0287 & 0.0006 & 0.0124 \\
\hline $\min$ & 0.0932 & 0.0001 & -0.9329 & 0.0000 & -1.0000 & 0.0932 & 0.0001 & -0.9329 & 0.0000 & -1.0000 & 0.1272 & 0.0016 & -0.7329 & 0.1339 & -1.0000 \\
\hline \multirow[t]{3}{*}{$\max$} & 0.1735 & 0.9742 & 0.8438 & 2.6176 & 0.6873 & 0.1615 & 0.9742 & 0.8438 & 2.6176 & 0.6026 & 0.1735 & 0.8663 & 0.6647 & 1.7718 & 0.6873 \\
\hline & \multicolumn{15}{|c|}{ Systemic Phase: September 2008 - March 2009} \\
\hline & $\sigma_{\eta_{t}}$ & $\alpha$ & $\beta$ & $\sigma_{\epsilon_{t}}$ & $\rho_{\eta_{t}, \epsilon_{t}}$ & $\sigma_{\eta_{t}}$ & $\alpha$ & $\beta$ & $\sigma_{\epsilon_{t}}$ & $\rho_{\eta_{t}, \epsilon_{t}}$ & $\sigma_{\eta_{t}}$ & $\alpha$ & $\beta$ & $\sigma_{\epsilon_{t}}$ & $\rho_{\eta_{t}, \epsilon_{t}}$ \\
\hline mean & 0.1417 & 0.4251 & 0.0120 & 1.1036 & -0.4663 & 0.1332 & 0.4474 & 0.0128 & 1.1110 & -0.5186 & 0.1767 & 0.3331 & 0.0087 & 1.0730 & -0.2503 \\
\hline std & 0.0008 & 0.0117 & 0.0301 & 0.0108 & 0.0609 & 0.0008 & 0.0081 & 0.0336 & 0.0120 & 0.0669 & 0.0009 & 0.0210 & 0.0016 & 0.0010 & 0.0002 \\
\hline $\min$ & 0.0704 & 0.0007 & -0.7421 & 0.0000 & -1.0000 & 0.0704 & 0.0019 & -0.7421 & 0.0000 & -1.0000 & 0.1432 & 0.0007 & -0.6698 & 0.1916 & -1.0000 \\
\hline \multirow[t]{3}{*}{$\max$} & 0.2317 & 1.0000 & 0.8143 & 3.0000 & 0.9630 & 0.2116 & 1.0000 & 0.8143 & 3.0000 & 0.9630 & 0.2317 & 0.8576 & 0.7257 & 2.7136 & 0.7180 \\
\hline & \multicolumn{15}{|c|}{ Recovery Phase: April 2009 - December 2009} \\
\hline & $\sigma_{\eta_{t}}$ & $\alpha$ & $\beta$ & $\sigma_{\epsilon_{t}}$ & $\rho_{\eta_{t}, \epsilon_{t}}$ & $\sigma_{\eta_{t}}$ & $\alpha$ & $\beta$ & $\sigma_{\epsilon_{t}}$ & $\rho_{\eta_{t}, \epsilon_{t}}$ & $\sigma_{\eta_{t}}$ & $\alpha$ & $\beta$ & $\sigma_{\epsilon t}$ & $\rho_{\eta_{t}, \epsilon_{t}}$ \\
\hline mean & 0.0814 & 0.2757 & 0.2022 & 0.9441 & -0.4683 & 0.0798 & 0.3212 & 0.1770 & 1.0334 & -0.5644 & 0.0878 & 0.0874 & 0.3066 & 0.5751 & -0.0712 \\
\hline std & 0.0003 & 0.0011 & 0.0109 & 0.0393 & 0.3498 & 0.0002 & 0.0012 & 0.0113 & 0.0021 & 0.3858 & 0.0003 & 0.0003 & 0.0095 & 0.0898 & 0.0001 \\
\hline $\min$ & 0.0395 & 0.0000 & -0.6071 & 0.0001 & -1.0000 & 0.0395 & 0.0000 & -0.6071 & 0.0001 & -1.0000 & 0.0584 & 0.0000 & -0.4193 & 0.0004 & -0.9235 \\
\hline \multirow[t]{3}{*}{$\max$} & 0.1204 & 0.9034 & 0.8363 & 2.6808 & 1.0000 & 0.1204 & 0.9034 & 0.8363 & 2.6808 & 1.0000 & 0.1171 & 0.6647 & 0.5654 & 1.8897 & 0.2541 \\
\hline & \multicolumn{15}{|c|}{ Sovereign Phase: January 2010 - September 2010} \\
\hline & $\sigma_{\eta_{t}}$ & $\alpha$ & $\beta$ & $\sigma_{\epsilon_{t}}$ & $\rho_{\eta_{t}, \epsilon_{t}}$ & $\sigma_{\eta_{t}}$ & $\alpha$ & $\beta$ & $\sigma_{\epsilon_{t}}$ & $\rho_{\eta_{t}, \epsilon_{t}}$ & $\sigma_{\eta_{t}}$ & $\alpha$ & $\beta$ & $\sigma_{\epsilon_{t}}$ & $\rho_{\eta_{t}, \epsilon_{t}}$ \\
\hline mean & 0.0867 & 0.4431 & -0.0105 & 1.2909 & -0.3859 & 0.0786 & 0.4696 & -0.0189 & 1.3044 & -0.4796 & 0.1204 & 0.3339 & 0.0244 & 1.2351 & 0.0010 \\
\hline std & 0.0002 & 0.0008 & 0.0011 & 0.0023 & 0.0684 & 0.0003 & 0.0009 & 0.0012 & 0.0025 & 0.0765 & 0.0001 & 0.0003 & 0.0003 & 0.0016 & 0.0012 \\
\hline $\min$ & 0.0323 & 0.0075 & -0.8546 & 0.0387 & -1.0000 & 0.0323 & 0.0075 & -0.7715 & 0.0387 & -1.0000 & 0.0813 & 0.0098 & -0.8546 & 0.2522 & -0.6606 \\
\hline $\max$ & 0.2539 & 1.0000 & 0.7076 & 2.8260 & 0.9970 & 0.2539 & 1.0000 & 0.7076 & 2.8260 & 0.9859 & 0.1730 & 0.9394 & 0.6083 & 2.7752 & 0.9970 \\
\hline
\end{tabular}


Table 3: Empirical Correlations

This table presents the mean, the minimum and the maximum of the sample correlation between the model-implied CDS premium and respectively the relative liquidity premium $\rho\left(S_{t}^{\text {def }}, R_{t}\right)$, the ask liquidity premium $\rho\left(S_{t}^{\text {def }}, S L_{t}^{a s k}\right)$ and the bid liquidity premium $\rho\left(S_{t}^{\text {def }}, S L_{t}^{\text {bid }}\right)$.

\begin{tabular}{|c|c|c|c|c|c|c|c|c|c|}
\hline & \multicolumn{3}{|c|}{ ALL } & \multicolumn{3}{|c|}{ NON-FINANCIALS } & \multicolumn{3}{|c|}{ FINANCIALS } \\
\hline & \multicolumn{9}{|c|}{ Pre-crisis Phase: January 2004 - July 2007} \\
\hline & $\rho\left(S_{t}^{\operatorname{def}}, R_{t}\right)$ & $\rho\left(S_{t}^{\operatorname{def}}, S L_{t}^{a s k}\right)$ & $\rho\left(S_{t}^{\text {def }}, S L_{t}^{\text {bid }}\right)$ & $\rho\left(S_{t}^{\operatorname{def}}, R_{t}\right)$ & $\rho\left(S_{t}^{\text {def }}, S L_{t}^{a s k}\right)$ & $\rho\left(S_{t}^{\text {def }}, S L_{t}^{b i d}\right)$ & $\rho\left(S_{t}^{\operatorname{def}}, R_{t}\right)$ & $\rho\left(S_{t}^{\text {def }}, S L_{t}^{a s k}\right)$ & $\rho\left(S_{t}^{\text {def }}, S L_{t}^{b i d}\right)$ \\
\hline mean & -0.0880 & 0.3266 & 0.4771 & -0.1324 & 0.2429 & 0.4172 & -0.0773 & 0.3469 & 0.4916 \\
\hline $\min$ & -0.8140 & -0.1976 & -0.1154 & -0.8140 & -0.0966 & 0.1305 & -0.5667 & -0.1976 & -0.1154 \\
\hline \multirow[t]{3}{*}{$\max$} & 0.3840 & 0.7897 & 0.8987 & 0.1028 & 0.5010 & 0.5799 & 0.3840 & 0.7897 & 0.8987 \\
\hline & \multicolumn{9}{|c|}{ Subprime Phase: August 2007 - August 2008} \\
\hline & $\rho\left(S_{t}^{\text {def }}, R_{t}\right)$ & $\rho\left(S_{t}^{\text {def }}, S L_{t}^{a s k}\right)$ & $\rho\left(S_{t}^{\text {def }}, S L_{t}^{\text {bid }}\right)$ & $\rho\left(S_{t}^{\text {def }}, R_{t}\right)$ & $\rho\left(S_{t}^{\text {def }}, S L_{t}^{a s k}\right)$ & $\rho\left(S_{t}^{\text {def }}, S L_{t}^{\text {bid }}\right)$ & $\rho\left(S_{t}^{\text {def }}, R_{t}\right)$ & $\rho\left(S_{t}^{\text {def }}, S L_{t}^{a s k}\right)$ & $\rho\left(S_{t}^{\text {def }}, S L_{t}^{\text {bid }}\right)$ \\
\hline mean & -0.0663 & 0.3982 & 0.6393 & 0.0309 & 0.3932 & 0.5360 & -0.0899 & 0.3994 & 0.6643 \\
\hline $\min$ & -0.5749 & -0.1829 & -0.0667 & -0.3742 & -0.0869 & -0.0134 & -0.5749 & -0.1829 & -0.0667 \\
\hline \multirow[t]{3}{*}{$\max$} & 0.6450 & 0.8219 & 0.9212 & 0.5262 & 0.6895 & 0.7360 & 0.6450 & 0.8219 & 0.9212 \\
\hline & \multicolumn{9}{|c|}{ Systemic Phase: September 2008 - March 2009} \\
\hline & $\rho\left(S_{t}^{\text {def }}, R_{t}\right)$ & $\rho\left(S_{t}^{d e f}, S L_{t}^{a s k}\right)$ & $\rho\left(S_{t}^{\text {def }}, S L_{t}^{\text {bid }}\right)$ & $\rho\left(S_{t}^{\text {def }}, R_{t}\right)$ & $\rho\left(S_{t}^{\text {def }}, S L_{t}^{a s k}\right)$ & $\rho\left(S_{t}^{\text {def }}, S L_{t}^{\text {bid }}\right)$ & $\rho\left(S_{t}^{\text {def }}, R_{t}\right)$ & $\rho\left(S_{t}^{\text {def }}, S L_{t}^{a s k}\right)$ & $\rho\left(S_{t}^{\text {def }}, S L_{t}^{\text {bid }}\right)$ \\
\hline mean & -0.0169 & 0.3054 & 0.3696 & 0.1693 & 0.3121 & 0.1686 & -0.0620 & 0.3038 & 0.4183 \\
\hline $\min$ & -0.6636 & -0.5418 & -0.4189 & -0.4950 & -0.2604 & -0.3229 & -0.6636 & -0.5418 & -0.4189 \\
\hline \multirow[t]{3}{*}{$\max$} & 0.7226 & 0.9125 & 0.9107 & 0.6912 & 0.7507 & 0.7734 & 0.7226 & 0.9125 & 0.9107 \\
\hline & \multicolumn{9}{|c|}{ Recovery Phase: April 2009 - December 2009} \\
\hline & $\rho\left(S_{t}^{\text {def }}, R_{t}\right)$ & $\rho\left(S_{t}^{\text {def }}, S L_{t}^{a s k}\right)$ & $\rho\left(S_{t}^{\text {def }}, S L_{t}^{b i d}\right)$ & $\rho\left(S_{t}^{\text {def }}, R_{t}\right)$ & $\rho\left(S_{t}^{\text {def }}, S L_{t}^{a s k}\right)$ & $\rho\left(S_{t}^{\text {def }}, S L_{t}^{b i d}\right)$ & $\rho\left(S_{t}^{\text {def }}, R_{t}\right)$ & $\rho\left(S_{t}^{\text {def }}, S L_{t}^{a s k}\right)$ & $\rho\left(S_{t}^{\text {def }}, S L_{t}^{b i d}\right)$ \\
\hline mean & 0.0380 & 0.4115 & 0.4511 & 0.0148 & 0.3030 & 0.5085 & 0.0437 & 0.4378 & 0.4372 \\
\hline $\min$ & -0.5446 & -0.3882 & -0.3138 & -0.5342 & -0.3555 & -0.0932 & -0.5446 & -0.3882 & -0.3138 \\
\hline \multirow[t]{3}{*}{$\max$} & 0.9471 & 0.9002 & 0.9164 & 0.6966 & 0.7483 & 0.8570 & 0.9471 & 0.9002 & 0.9164 \\
\hline & \multicolumn{9}{|c|}{ Sovereign Phase: January 2010 - September 2010} \\
\hline & $\rho\left(S_{t}^{\text {def }}, R_{t}\right)$ & $\rho\left(S_{t}^{\text {def }}, S L_{t}^{\text {ask }}\right)$ & $\rho\left(S_{t}^{\text {def }}, S L_{t}^{\text {bid }}\right)$ & $\rho\left(S_{t}^{\text {def }}, R_{t}\right)$ & $\rho\left(S_{t}^{\text {def }}, S L_{t}^{\text {ask }}\right)$ & $\rho\left(S_{t}^{\text {def }}, S L_{t}^{\text {bid }}\right)$ & $\rho\left(S_{t}^{\text {def }}, R_{t}\right)$ & $\rho\left(S_{t}^{\text {def }}, S L_{t}^{a s k}\right)$ & $\rho\left(S_{t}^{\text {def }}, S L_{t}^{b i d}\right)$ \\
\hline mean & 0.1044 & 0.3882 & 0.2810 & 0.1089 & 0.4888 & 0.5177 & 0.1033 & 0.3639 & 0.2237 \\
\hline $\min$ & -0.5415 & -0.3563 & -0.4752 & -0.5221 & 0.2468 & -0.0286 & -0.5415 & -0.3563 & -0.4752 \\
\hline $\max$ & 0.6914 & 0.8622 & 0.9388 & 0.3736 & 0.7496 & 0.9335 & 0.6914 & 0.8622 & 0.9388 \\
\hline
\end{tabular}




\section{Table 4: Distributional properties of model-implied CDS and liquidity premia}

This table shows the mean, the minimum, the maximum and the median of the timeseries average of the model-implied CDS premium $S_{t}^{\text {def }}$, the ratio of the protection seller's liquidity premium to the bid-ask spread $R_{t}$, the relative ask liquidity premium $S L_{t, r e l}^{a s k}=$ $\frac{S L_{t}^{a s k}}{S_{t}^{\text {def }}}$, the relative bid liquidity premium $S L_{t, r e l}^{\text {bid }}=\frac{S L_{t}^{\text {bid }}}{S_{t}^{\text {def }}}$ and the deviation of the mid quotes from the model-implied CDS premia $\Delta S_{t}=S_{t}^{\text {mid }}-S_{t}^{\text {def }}$.

\begin{tabular}{|c|c|c|c|c|c|c|c|c|c|c|c|c|c|c|c|}
\hline & \multicolumn{5}{|c|}{ ALL } & \multicolumn{5}{|c|}{ NON-FINANCIALS } & \multicolumn{5}{|c|}{ FINANCIALS } \\
\hline & \multicolumn{15}{|c|}{$\begin{array}{c}\text { Pre-crisis Phase } \\
\text { January } 2004 \text { - July } 2007\end{array}$} \\
\hline & $S_{t}^{\text {def }}$ & $R_{t}$ & $S L_{t, r e l}^{a s k}$ & $S L_{t, \text { rel }}^{\text {bid }}$ & $\Delta S_{t}$ & $S_{t}^{\text {def }}$ & $R_{t}$ & $S L_{t, r e l}^{a s k}$ & $S L_{t, r e l}^{\text {bid }}$ & $\Delta S_{t}$ & $S_{t}^{\text {def }}$ & $R_{t}$ & $S L_{t, r e l}^{a s k}$ & $S L_{t, r e l}^{\text {bid }}$ & $\Delta S_{t}$ \\
\hline mean & 34.37 & 0.257 & 0.033 & 0.100 & -0.80 & 38.92 & 0.264 & 0.031 & 0.092 & -0.84 & 15.85 & 0.228 & 0.043 & 0.133 & -0.64 \\
\hline $\min$ & 3.81 & 0.000 & 0.000 & 0.000 & -20.00 & 3.82 & 0.000 & 0.000 & 0.000 & -20.00 & 3.81 & 0.000 & 0.000 & 0.000 & -5.62 \\
\hline $\max$ & 539.21 & 1.000 & 1.181 & 0.993 & 29.83 & 539.21 & 1.000 & 1.181 & 0.993 & 29.83 & 60.83 & 0.999 & 1.108 & 0.992 & 1.50 \\
\hline median & 27.57 & 0.244 & 0.027 & 0.085 & -0.73 & 31.49 & 0.252 & 0.026 & 0.077 & -0.76 & 13.95 & 0.224 & 0.033 & 0.120 & -0.60 \\
\hline std & 31.43 & 0.151 & 0.038 & 0.071 & 0.82 & 33.33 & 0.154 & 0.034 & 0.068 & 0.89 & 7.63 & 0.137 & 0.050 & 0.070 & 0.41 \\
\hline \multirow[t]{3}{*}{ skew } & 5.16 & 0.620 & 11.497 & 3.601 & -1.16 & 5.04 & 0.629 & 12.647 & 3.928 & -1.01 & 1.05 & 0.453 & 9.035 & 3.704 & -0.89 \\
\hline & \multicolumn{15}{|c|}{$\begin{array}{c}\text { Subprime Phase } \\
\text { August } 2007 \text { - August } 2008\end{array}$} \\
\hline & $S_{t}^{\text {def }}$ & $R_{t}$ & $S L_{t, r e l}^{a s k}$ & $S L_{t, \text { rel }}^{\text {bid }}$ & $\Delta S_{t}$ & $S_{t}^{\text {def }}$ & $R_{t}$ & $S L_{t, r e l}^{a s k}$ & $S L_{t, r e l}^{\text {bid }}$ & $\Delta S_{t}$ & $S_{t}^{\text {def }}$ & $R_{t}$ & $S L_{t, r e l}^{a s k}$ & $S L_{t, r e l}^{b i d}$ & $\Delta S_{t}$ \\
\hline mean & 70.12 & 0.235 & 0.021 & 0.065 & -1.30 & 70.15 & 0.235 & 0.021 & 0.062 & -1.24 & 70.00 & 0.236 & 0.024 & 0.076 & -1.54 \\
\hline $\min$ & 9.38 & 0.000 & 0.000 & 0.000 & -10.00 & 9.38 & 0.000 & 0.000 & 0.000 & -10.00 & 17.99 & 0.000 & 0.000 & 0.000 & -7.50 \\
\hline $\max$ & 391.67 & 1.000 & 0.313 & 0.277 & 9.78 & 391.67 & 1.000 & 0.313 & 0.277 & 9.78 & 244.25 & 1.000 & 0.258 & 0.258 & 5.69 \\
\hline median & 58.99 & 0.174 & 0.013 & 0.060 & -1.38 & 58.19 & 0.169 & 0.013 & 0.058 & -1.33 & 62.99 & 0.187 & 0.016 & 0.069 & -1.66 \\
\hline std & 41.93 & 0.227 & 0.025 & 0.034 & 1.42 & 43.51 & 0.227 & 0.025 & 0.032 & 1.37 & 34.70 & 0.227 & 0.028 & 0.040 & 1.59 \\
\hline \multirow[t]{3}{*}{ skew } & 1.79 & 0.981 & 2.503 & 1.290 & 0.15 & 1.86 & 1.008 & 2.421 & 1.341 & 0.13 & 1.12 & 0.869 & 2.635 & 0.957 & 0.32 \\
\hline & \multicolumn{15}{|c|}{$\begin{array}{c}\text { Systemic Phase } \\
\text { September } 2008 \text { - March } 2009\end{array}$} \\
\hline & $S_{t}^{\text {def }}$ & $R_{t}$ & $S L_{t, r e l}^{a s k}$ & $S L_{t, r e l}^{b i d}$ & $\Delta S_{t}$ & $S_{t}^{\text {def }}$ & $R_{t}$ & $S L_{t, r e l}^{a s k}$ & $S L_{t, r e l}^{b i d}$ & $\Delta S_{t}$ & $S_{t}^{\text {def }}$ & $R_{t}$ & $S L_{t, r e l}^{a s k}$ & $S L_{t, r e l}^{b i d}$ & $\Delta S_{t}$ \\
\hline mean & 178.68 & 0.417 & 0.038 & 0.053 & -0.46 & 185.06 & 0.444 & 0.041 & 0.051 & -0.11 & 152.34 & 0.305 & 0.024 & 0.062 & -1.91 \\
\hline $\min$ & 22.18 & 0.000 & 0.000 & 0.000 & -72.05 & 22.18 & 0.000 & 0.000 & 0.000 & -72.01 & 49.99 & 0.000 & 0.000 & 0.000 & -24.99 \\
\hline $\max$ & 2958.54 & 1.000 & 0.287 & 0.205 & 76.94 & 2958.54 & 1.000 & 0.287 & 0.193 & 76.94 & 790.17 & 1.000 & 0.129 & 0.205 & 14.86 \\
\hline median & 126.57 & 0.386 & 0.029 & 0.048 & -1.14 & 128.12 & 0.417 & 0.033 & 0.046 & -0.79 & 123.05 & 0.240 & 0.019 & 0.055 & -2.61 \\
\hline std & 181.20 & 0.299 & 0.034 & 0.035 & 5.92 & 194.36 & 0.300 & 0.035 & 0.035 & 6.33 & 107.63 & 0.266 & 0.023 & 0.037 & 3.42 \\
\hline \multirow[t]{3}{*}{ skew } & 5.48 & 0.372 & 1.512 & 0.737 & 1.89 & 5.34 & 0.282 & 1.425 & 0.715 & 1.79 & 2.73 & 0.760 & 1.480 & 0.804 & 0.44 \\
\hline & \multicolumn{15}{|c|}{$\begin{array}{l}\text { Recovery Phase } \\
\text { April } 2009 \text { - December } 2009\end{array}$} \\
\hline & $S_{t}^{\text {def }}$ & $R_{t}$ & $S L_{t, r e l}^{a s k}$ & $S L_{t, r e l}^{b i d}$ & $\Delta S_{t}$ & $S_{t}^{\text {def }}$ & $R_{t}$ & $S L_{t, r e l}^{a s k}$ & $S L_{t, r e l}^{b i d}$ & $\Delta S_{t}$ & $S_{t}^{\text {def }}$ & $R_{t}$ & $S L_{t, r e l}^{a s k}$ & $S L_{t, r e l}^{b i d}$ & $\Delta S_{t}$ \\
\hline mean & 103.62 & 0.321 & 0.027 & 0.056 & -1.15 & 102.64 & 0.370 & 0.032 & 0.057 & -0.92 & 107.67 & 0.120 & 0.007 & 0.055 & -2.11 \\
\hline $\min$ & 17.83 & 0.000 & 0.000 & 0.000 & -19.60 & 17.83 & 0.000 & 0.000 & 0.000 & -19.60 & 29.98 & 0.000 & 0.000 & 0.000 & -14.16 \\
\hline $\max$ & 1313.28 & 1.000 & 0.332 & 0.230 & 26.45 & 1313.28 & 1.000 & 0.332 & 0.230 & 26.45 & 629.39 & 1.000 & 0.094 & 0.181 & 14.46 \\
\hline median & 82.82 & 0.259 & 0.019 & 0.052 & -1.57 & 79.67 & 0.359 & 0.027 & 0.051 & -0.98 & 90.47 & 0.017 & 0.001 & 0.053 & -2.20 \\
\hline & 77.62 & 0.305 & 0.032 & 0.035 & 2.80 & 80.77 & 0.303 & 0.033 & 0.037 & 2.91 & 62.82 & 0.223 & 0.013 & 0.026 & 2.04 \\
\hline \multirow[t]{3}{*}{ skew } & 4.83 & 0.517 & 2.239 & 0.924 & 0.74 & 4.97 & 0.290 & 2.120 & 0.886 & 0.62 & 3.25 & 2.230 & 2.932 & 1.006 & 1.04 \\
\hline & \multicolumn{15}{|c|}{$\begin{array}{c}\text { Sovereign Phase } \\
\text { January } 2010 \text { - September } 2010\end{array}$} \\
\hline & $S_{t}^{\text {def }}$ & $R_{t}$ & $S L_{t, r e l}^{a s k}$ & $S L_{, \text {rel }}^{\text {bid }}$ & $\Delta S_{t}$ & $S_{t}^{\text {def }}$ & $R_{t}$ & $S L_{t, r e l}^{a s k}$ & $S L_{t, r e l}^{\text {bid }}$ & $\Delta S_{t}$ & $S_{t}^{\text {def }}$ & $R_{t}$ & $S L_{t, r e l}^{a s k}$ & $S L_{t, r e l}^{b i d}$ & $\Delta S_{t}$ \\
\hline mean & 101.65 & 0.438 & 0.029 & 0.035 & -0.35 & 95.61 & 0.469 & 0.032 & 0.035 & -0.12 & 126.59 & 0.307 & 0.016 & 0.036 & -1.33 \\
\hline $\min$ & 20.30 & 0.000 & 0.000 & 0.000 & -17.07 & 20.30 & 0.000 & 0.000 & 0.000 & -9.60 & 33.67 & 0.000 & 0.000 & 0.000 & -17.07 \\
\hline $\max$ & 601.49 & 1.000 & 0.168 & 0.186 & 12.93 & 586.92 & 1.000 & 0.168 & 0.186 & 12.93 & 601.49 & 1.000 & 0.080 & 0.110 & 8.92 \\
\hline median & 86.92 & 0.408 & 0.024 & 0.033 & -0.46 & 79.57 & 0.441 & 0.027 & 0.033 & -0.28 & 111.38 & 0.272 & 0.013 & 0.035 & -1.19 \\
\hline std & 58.82 & 0.272 & 0.023 & 0.021 & 1.99 & 54.48 & 0.273 & 0.023 & 0.023 & 1.88 & 68.76 & 0.222 & 0.013 & 0.015 & 2.12 \\
\hline skew & 2.84 & 0.409 & 1.328 & 0.897 & -0.07 & 2.68 & 0.318 & 1.213 & 0.911 & 0.70 & 3.18 & 0.686 & 1.333 & 0.465 & -1.95 \\
\hline
\end{tabular}


Table 5: Panel regressions explaining the effect of the financial crisis on the relative bid-ask spread, the model-implied default and the liquidity premia

This Table shows the results of random effects panel regressions and explains the impact of the crises periods on the model-implied CDS premium $S_{t}^{\text {def }}$, the relative bid-ask spread $B A_{t, r e l}^{\text {def }}$, the ratio of the liquidity premia $R$, the relative liquidity premium of the protection seller $S L_{t, r e l}^{a s k}$, and the relative liquidity premium of the protection buyer $S L_{t, r e l}^{b i d}$. The relative bid-ask spread $B A_{t, r e l}^{d e f}=\frac{B A_{t}}{S_{t}^{\text {def }}}$ is computed as the ratio of the bid-ask spread to the model-implied CDS premium. The ratio $R_{t}=\frac{S L_{t}^{a s k}}{B A_{t}}$ represents the proportion of the bid-ask spread attributed to the protection seller and equals the ratio of the ask liquidity premium to the bid-ask spread. $S L_{t, r e l}^{a s k}=\frac{S L_{t}^{a s k}}{S_{t}^{\text {def }}}$ is the liquidity premium of the protection seller and $S L_{t, r e l}^{\text {bid }}=\frac{S L_{t}^{\text {bid }}}{S_{t}^{\text {def }}}$ is the liquidity premium of the protection seller buyer relative to the model-implied CDS premium. $\Delta S_{t}$ designates the difference between the mid quote and the model-implied CDS premium. $x_{t}^{\text {def }}$ is defined as $x_{t}^{\text {def }}=-1000 e^{-S_{t}^{d e f}}$ such that the model default premium is linearly related to the explained variables.

\begin{tabular}{l|rr|rr|rr|rr|rr|rr}
\hline & $S_{t}^{\text {def }}$ & t-stat & \multicolumn{1}{|c}{$R_{t}$} & t-stat & $B A_{t, \text { rel }}^{\text {def }}$ & t-stat & $S L_{t, \text { rel }}^{\text {ask }}$ & t-stat & $S L_{t, r \text { rel }}^{\text {bid }}$ & t-stat & $\Delta S_{t}$ & t-stat \\
\hline$S_{t}^{\text {def }}$ & & & 0.0001 & 1.30 & & & & & & & & \\
$x_{t}^{\text {def }}$ & & & & & -0.0230 & -9.63 & -0.0027 & -1.96 & -0.0204 & -12.76 & -0.0207 & -1.63 \\
financial & -24.21 & -7.51 & -0.0315 & -1.12 & 0.0494 & 4.93 & 0.0113 & 2.16 & 0.0381 & 4.73 & 0.2566 & 2.61 \\
subprime & 30.09 & 10.30 & -0.0298 & -1.33 & -0.0385 & -10.63 & -0.0103 & -4.65 & -0.0282 & -7.75 & -0.3387 & -2.59 \\
systemic & 145.00 & 9.09 & 0.1686 & 5.11 & -0.0294 & -6.10 & 0.0104 & 3.18 & -0.0398 & -7.95 & 0.7857 & 1.70 \\
recovery & 62.58 & 10.71 & 0.1021 & 3.40 & -0.0326 & -6.58 & 0.0015 & 0.44 & -0.0340 & -7.02 & -0.0228 & -0.12 \\
sovereign & 55.56 & 12.59 & 0.2022 & 8.50 & -0.0544 & -11.35 & 0.0010 & 0.43 & -0.0554 & -11.54 & 0.7817 & 5.27 \\
fin_sub & 24.07 & 6.06 & 0.0327 & 0.72 & -0.0327 & -3.52 & -0.0082 & -1.44 & -0.0245 & -2.82 & -0.5611 & -2.09 \\
fin_sys & -8.51 & -0.34 & -0.1045 & -1.84 & -0.0557 & -5.09 & -0.0285 & -4.02 & -0.0272 & -2.92 & -2.0564 & -3.33 \\
fin_rec & 29.24 & 2.71 & -0.2187 & -4.43 & -0.0766 & -6.74 & -0.0369 & -6.22 & -0.0397 & -4.26 & -1.4448 & -4.99 \\
fin_sov & 55.19 & 4.46 & -0.1335 & -2.78 & -0.0646 & -6.21 & -0.0271 & -4.47 & -0.0375 & -4.55 & -1.4665 & -4.20 \\
const & 40.06 & 13.10 & 0.2584 & 19.36 & 0.1215 & 22.93 & 0.0309 & 18.52 & 0.0906 & 18.81 & -0.8968 & -11.37 \\
Adj R sqd & 0.29 & & 0.1369 & & 0.2267 & & 0.0527 & & 0.2770 & & 0.0342 & \\
N Obs & 41654 & & 41654 & & 41654 & & 41654 & & 41654 & & 41654 & \\
\hline
\end{tabular}




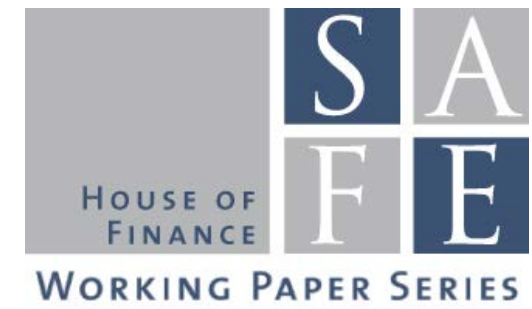

\section{Recent Issues}

No. 172 Ahmed Khalifa, Massimiliano Caporin, Michele Costola, Shawkat Hammoudeh

No. 171 Michael Donadelli, Patrick Grüning

No. 169 Max Groneck, Alexander Ludwig, Alexander Zimper

No. 168 Guido Friebel, Marie Lalanne, Bernard Richter, Peter Schwardmann, Paul Seabright

No. 167 Felix Noth, Ulrich Schüwer

No. 166 Monica Billio, Massimiliano Caporin, Roberto Panzica, Loriana Pelizzon

No. 165 Giovani Bonaccolto, Massimiliano Caporin, Roberto Panzica

No. 164 Raimond Maurer, Olivia S. Mitchell, Ralph Rogalla, Tatjana Schimetschek

No. 163 Giuliano Curatola, Michael Donadelli, Patrick Grüning

No. 162 Gabriele Camera, Alessandro Gioffré

No. 161 Tobin Hanspal

No. 160 Domenico Rocco Cambrea, Stefano Colonnello, Giuliano Curatola, Giulia Fantini
Systemic Risk for Financial Institutions of Major Petroleum-based Economies: The Role of Oil

Innovation Dynamics and Fiscal Policy: Implications for Growth, Asset Prices, and Welfare

The Impact of Biases in Survival Beliefs on Savings Behavior

Women form social networks more selectively and less opportunistically than men

Natural disaster and bank stability: Evidence from the U.S. financial system

The impact of network connectivity on factor exposures, asset pricing and portfolio diversification

Estimation and model-based combination of causality networks

Optimal Social Security Claiming Behavior under Lump Sum Incentives: Theory and Evidence

Technology Trade with Asymmetric Tax Regimes and Heterogeneous Labor Markets: Implications for Macro Quantities and Asset Prices

Asymmetric Social Norms

The Effect of Personal Financing Disruptions on Entrepreneurship

Abandon Ship: Inside Debt and Risk-Taking Incentives in Bad Times 